AperTO - Archivio Istituzionale Open Access dell'Università di Torino

Measuring the Underground Economy with the Currency Demand Approach: A Reinterpretation of the Methodology, With an Application to Italy

This is the author's manuscript

Original Citation:

Availability:

This version is available http://hdl.handle.net/2318/132693

since 2016-09-14T11:27:42Z

Published version:

DOI:10.1111/roiw.12019

Terms of use:

Open Access

Anyone can freely access the full text of works made available as "Open Access". Works made available under a Creative Commons license can be used according to the terms and conditions of said license. Use of all other works requires consent of the right holder (author or publisher) if not exempted from copyright protection by the applicable law. 


\section{(3) \\ UNIVERSITÀ DEGLI STUDI DI TORINO}

This is an author version of the contribution published on:

Questa è la versione dell'autore dell'opera:

G. Ardizzi, C. Petraglia, M. Piacenza, G. Turati, "Measuring the Underground Economy with the Currency Demand Approach: A Reinterpretation of the Methodology, with an Application to Italy", Review of Income and Wealth, vol. 60, n. 4, December 2014, pp. 747-772.

The definitive version is available at:

La versione definitiva è disponibile alla URL:

http://onlinelibrary.wiley.com/doi/10.1111/roiw.12019/abstract 


\title{
Measuring the Underground Economy with the Currency Demand Approach A Reinterpretation of the methodology, with an application to Italy ${ }^{\star}$
}

\author{
Guerino ARDIZZI \\ (Bank of Italy, guerino.ardizzi@bancaditalia.it) \\ Carmelo PETRAGLIA \\ (University of Basilicata, carmelo.petraglia@unibas.it) \\ Massimiliano PIACENZA \\ (University of Torino, massimiliano.piacenza@unito.it) \\ Gilberto TURATI* \\ (University of Torino, gilberto.turati@unito.it)
}

\begin{abstract}
We contribute to the debate on how to assess the size of the underground (or shadow) economy by proposing a reinterpretation of the traditional Currency Demand Approach (CDA) à la Tanzi. In particular, we introduce three main innovations. First, we take a direct measure of the value of cash transactions - the flow of cash withdrawn from bank accounts relative to total noncash payments - as the dependent variable in the money demand equation. This allows us to avoid unrealistic assumptions on the velocity of money and the absence of any irregular transaction in a given year, overcoming two severe critiques to the traditional CDA. Second, in place of the tax burden level, usually intended as the main motivation for non-compliance, we include among the covariates two direct indicators of detected tax evasion. Finally, we control also for the role of illegal production considering crimes like drug dealing and prostitution, which - jointly with the shadow economy - contributes to the larger aggregate of the non-observed economy and represents a significant component of total cash payments. We propose then an application of this 'modified CDA' to a panel of 91 Italian provinces for the years 2005-2008.
\end{abstract}

Keywords: Underground economy, Currency Demand Approach, Cash transactions, Tax evasion, Illegal production

JEL classification: E26, E41, H26, K42, O17

\footnotetext{
“We wish to thank two anonymous referees, Fabio Bagliano, Mark Crain, Domenico Depalo, Fabio Padovano, Michael Pickhardt, Luca Salvadori, Alessandro Santoro, Jordi Sardà, Friedrich Schneider, Paolo Sestito, Brigitte Unger, Roberta Zizza, and all seminar participants at the Workshop on Macroeconomic and Policy Implications of Underground Economy and Tax Evasion (Bocconi University, 2012), the $2^{\text {nd }}$ World Congress of the Public Choice Societies (Miami, 2012), the 52nd Annual Conference of the Italian Economic Association (Roma Tre University, 2011), the 2011 Conference on Shadow Economy, Tax Evasion and Money Laundering (Münster University, Germany) and the Lunch Seminar held at the Bank of Italy (Roma, 2011), for their helpful comments. Usual disclaimers apply.

${ }^{*}$ Corresponding author: University of Torino, Department of Economics and Statistics, Corso Unione Sovietica 218 bis, 10134 Torino - ITALY. Phone: +39.011.6706046; fax: +39.011.6706062.
} 


\section{Introduction}

The Currency Demand Approach (CDA) is the most popular method to estimate the underground (or shadow) economy among the so-called indirect macroeconomic approaches. Originally suggested by Cagan (1958), the CDA was subsequently refined and applied by Tanzi $(1980,1983)$ to the U.S. economy, and has been (and still is) widely adopted in the literature. ${ }^{1}$ The CDA measures the size of the shadow economy in two stages: the econometric estimation of an aggregate money demand equation, with a specific component related to cash transactions in the underground sector; and the computation of the value of these shadow transactions via the quantity theory of money. Schneider and Enste (2000, 2002) identify and discuss many substantial drawbacks of the CDA, pointing out three main criticisms of the basic assumptions of this methodology: the absence of any transactions in the underground economy in a given base year; the same velocity of money in both the official and the irregular economy; the excessive tax burden as the only determinant of the shadow economy.

The aim of this paper is to contribute to the debate on the measurement of the underground economy by proposing a reinterpretation of the CDA that overcomes all these three drawbacks. In particular, we propose a 'modified CDA' introducing three main innovations to the traditional methodology. First, we take a direct measure of the value of cash transactions (the flow of cash withdrawn from bank accounts relative to total noncash payments) as the dependent variable in the money demand equation, which avoid making specific assumption on the velocity of money and the absence of irregular transaction in a given year. Second, in place of the tax burden level, we include among the covariates two direct measures of 'detected' tax evasion, thus overcoming a serious problem of potential misspecification of the model due to the inability of considering all the relevant determinants of non-compliance. Finally, we also control for the influence of illegal production (considering crimes like drug dealing and prostitution), which represents a significant component of total cash payments and - jointly with shadow economy - contributes to the larger aggregate of non-observed economy (OECD, 2002). We then apply this 'modified CDA' to Italy, a country where the size of the underground economy is remarkable compared to other Western countries. The use of panel data for Italian provinces observed over the period 2005-2008 allows us to provide sub-national estimates of the

\footnotetext{
${ }^{1}$ Among the more recent contributions on this method, see Ahumada et al. $(2007,2008)$ and Ferwerda et al. (2010).
} 
two components of non-observed economy. To the best of our knowledge, this represents a further novelty of this work with respect to most of the current literature. ${ }^{2}$

The remainder of the paper is structured as follows. Section 2 provides a brief summary of the traditional CDA, and a discussion of the methodological innovations we introduce to reinterpret the traditional approach, showing how these help overcome (most of) the drawbacks highlighted by Schneider and Enste (2000, 2002). Section 3 deals with the theoretical considerations supporting our empirical model, introducing the key hypotheses to be tested in the estimations. In section 4 we present the application of our 'modified CDA' to Italy, discussing model specification and empirical results. We also propose a number of robustness checks to control whether our results are sensible to alternative model specifications. Besides country level estimates, we provide also disaggregated territorial estimates for country macroareas. Section 5 contains brief concluding remarks.

\section{Reinterpreting the traditional Currency Demand Approach}

Following the classification used in Schneider (2010a, 2011), three main methodology have been applied so far by researchers for the measurement of the shadow economy: 1) direct micro level procedures, such as surveys on firms and households $\left.{ }^{3} ; 2\right)$ indirect macro level procedures making use of aggregate data retrieved from national accounts, such as the CDA; 3) models that use statistical tools to estimate the shadow economy as an 'unobserved' variable, such as the Multiple-Indicators-Multiple-Causes (MIMIC) model ${ }^{4}$.

The CDA is by far the most popular within the above mentioned methodologies, carried out making a number of restrictive hypothesis though. Section 2.1 summarises the empirical strategy of the traditional CDA and, provided that our empirical analysis concerns the Italian provinces, briefly review the main studies aimed at estimating the size of the shadow economy in Italy by using the CDA method. Sections 2.2 discusses in detail the innovations of our methodology as compared to the traditional CDA.

\footnotetext{
${ }^{2}$ Buehn (2012) propose disaggregated territorial estimates for German districts, but the work is limited to shadow economy and neglects the role played by illegal production.

${ }^{3}$ Direct micro methods use surveys either on firms or households aiming to assess the size of shadow economy in specific sectors and/or specific categories of tax payers. For an exhaustive discussion on advantages and limits, see Mogensen et al. (1995).

4 The MIMIC assumes that the shadow economy remains an unobserved phenomenon (latent variable) whose causes and effects are observable but not directly measured. The MIMIC procedure produces only a ranking of the size and the development of the shadow economy, which implies the adoption of other methods in order to convert the relative index into estimates in percentage of official GDP. In particular, the CDA is used to calibrate the relative estimates into absolute ones. For further details on this estimation method, see Frey and WeckHannemann (1984), Giles (1999), Schneider e Enste (2002), Pickhardt and Sarda Pons (2006), Buehn et al. (2009), Schneider (2010a, 2011), Pickhardt and Sarda (2011) and Buehn and Schneider (2012).
} 


\subsection{The CDA in a nutshell}

The CDA measures the size of the shadow economy in two stages: 1) the econometric estimation of an aggregate money demand equation, with a specific component related to cash transactions in the underground sector; 2) the computation of the value of these shadow transactions via the quantity theory of money. The key assumptions for the first-stage estimation are that shadow transactions are settled in cash to avoid traceability, and that the main cause of the underground economy is a high tax burden. The CDA involves estimating the aggregate cash demand including among the regressors both standard explanatory variables of the preference for liquidity (like the interest rate on deposits) and specific variables identifying the determinants of the shadow economy (like the tax burden level). The demand for cash associated with shadow transactions is then computed as the difference between the estimated demand for cash in the full model and the demand obtained by setting to zero all the determinants of the underground economy (i.e., the demand for cash motivated only by regular transactions).

For instance, in the Tanzi $(1980,1983)$ application of the CDA to the U.S. economy, the dependent variable in the money demand equation is the cash to money supply ratio (a proxy for the stock of liquid assets $M$ in the Fisher equation). This ratio is regressed on three variables identifying the determinants of money demand for regular transactions (the share of wages paid in cash on the national income, the interest rate on savings deposits, and the average income per capita), plus the average tax rate on personal income, which is considered to be the sole determinant of the shadow transactions. Since a basic assumption of the CDA is that a higher tax burden stimulates a higher evasion, which in turn causes an increase in the demand for cash, the expected sign on the income tax rate is positive ${ }^{5}$. First stage estimation of the money demand equation confirms this view. In the second stage, the estimate of the underground economy to GDP is obtained by exploiting the Fisher equation $M \times V=P \times T$, where $M$ is the money supply (i.e., the stock of liquid assets available in the economy at a specific time), $V$ is the velocity of money, and the right-hand side is the value of total transactions in goods and services. Since $P \times T$ is unknown, the implementation of the Fisher equation requires to assume that the values of total transactions in goods and services is proxied by nominal GDP. Then, defining a base year in which the contribution of the underground economy to GDP is assumed

\footnotetext{
5 Notice that this introduces a causality issue in the traditional CDA, which is the source of further econometric critiques to this methodology (e.g., Breusch, 2005a,b). As will be discussed below, our re-interpretation reduces the CDA to a decomposition exercise in the spirit of, e.g., Wagstaff et al. (2003), hence avoiding also these technical problems.
} 
to be zero, the velocity of money $V$ is computed as the ratio between the official GDP and the stock of liquid assets. Assuming then that this velocity is the same for the regular economy and the shadow sector, the value of the latter is obtained by multiplying $V$ for the estimated 'excess demand' for cash.

Although the issue is of great concern for policy makers, there is a scant number of empirical studies on the size and the development of shadow economy in Italy. The official figures are delivered by the Italian National Statistical Office (ISTAT). In particular, the estimates of employment and value added generated by the shadow economy are obtained by applying the so called 'labour input method' pioneered by the ISTAT itself in the $1980 \mathrm{~s}^{6}$. The shadow economy is defined as that part of non-observed economy related to the legal production of goods and services hidden to Tax Authorities (ISTAT, 2010: 1). The exclusion of illegal economy from official figures is motivated by the difficulties and the resulting uncertainty of the estimate, which would make data from various countries little comparable. The latest figures are available for the period 2000-2008. The value added produced in the underground economy is estimated to be in 2008 between a minimum of 16.3\% (approximately 255 billion euros) and a maximum of $17.5 \%$ of GDP (about 275 billion euros). Overall, shadow activities seem to show a somewhat countercyclical pattern, with peaks reached in 2001 and 2008.

According to the results delivered by Schneider and Enste (2000, 2002) - perhaps the most known CDA studies delivering results for Italy - the shadow economy represents more than one-fourth of the officially measured GDP (above 25\% from mid-90s until 2000). More recent estimates obtained with the MIMIC approach provided by Buehn and Schneider (2012) are in line with these figures, showing a share of the shadow economy out of total GDP around $27 \%$ over the period 2000-2007. A general weakness of both studies rests in neglecting the issue of illegal production.

This weakness has been discussed by Zizza (2002), who estimates the size and the evolution of the shadow economy in Italy, by introducing a variable that explicitly controls for the impact of criminal activities on the demand for cash payments among the regressors of the standard CDA approach à la Tanzi. Using a relatively small number of observations (68; 1984-2000 quarterly data), the aggregate money demand equation is estimated by regressing the currencyto-GDP ratio on a measure of tax pressure (the sole determinant of the shadow economy), the

\footnotetext{
${ }^{6}$ As summarized by OECD (2002), the methods entails: 1) estimate the labour input underlying GDP estimates; 2) estimate the labour input based on household survey data; 3 ) convert the enterprise based (demand) and household based (supply) estimates of labour input into the same units of labour input; 4) compare the two sets of estimates. A surplus of labour input derived from the household source over that from the enterprise source is an indication of non-observed production.
} 
interest rate and an indicator of crime. The tax burden measure is given by the ratio of the sum of direct taxes and social security contributions to GDP. The crime indicator is given by the share of thefts and robberies out of the total number of reported crimes. The author argues that her results are consistent with the official figures provided by ISTAT for the same years once one excludes the demand for cash linked to criminal activities (14-17\%). This is an important point, since it suggests that not accounting for cash used in illegal activities can actually bias the estimates of the shadow economy. However, as we argue below, the indicator of crime based on the diffusion of thefts and robberies may not satisfactorily account for the use of cash in illegal transactions. Other indicators, together with a re-interpretation of the traditional CDA, are better suited to obtain more precise estimates of the underground economy.

\subsection{Reinterpreting the CDA}

The starting point of our reinterpretation of the CDA are the criticisms to most of the assumptions of the traditional CDA advanced by Schneider and Enste (2000, 2002). In particular, we focus here on three main issues: (1) the hypothesis of the absence of any transactions in the underground economy in a given base year, which is rather unrealistic; (2) the assumption of equality in the velocity of money for both the official and the irregular economy, which introduces a restriction in the estimation method not easily justifiable; (3) the hypothesis of the excessive tax burden as the only determinant of the shadow economy, which is also quite restrictive, since other factors - such as market regulation (especially the regulation of labour markets), the trust in political institutions, and the citizens' tax morale - can substantially affect the decision to participate in the underground sector.

To avoid these critiques, in this study we introduce three innovations as compared to the traditional CDA à la Tanzi. First, instead of using the stock of liquid assets as the dependent variable in the money demand equation $(M)$, here we take the flow of cash withdrawn from bank accounts with respect to total payments settled by instruments other than cash as a direct measure of cash transactions $(M \times V)$. This is a substantial modification of the model, which eliminates the need to make restrictive assumptions on the velocity of money $V$, hence allows us to avoid the correction recently proposed by Ahumada et al. (2007). In particular, we are able to overcome the critique (1), concerning the need to arbitrarily choose a base year for calculating the velocity of money, and the critique (2), concerning the equality assumption of the velocity of money in both the official economy and the shadow sector. Another important point to be made concerns the variation over time in the velocity of money, which has apparently slowed 
down in recent years. Notice that the cash withdrawals we refer to also help to deal with the problematic measurement of the stock of liquid assets in each country of the EMU zone after the introduction of the euro, which can severely limit the application of the traditional CDA for countries in this area. A detailed discussion on the empirical merits of our direct measure of cash transactions with respect to the traditional money supply measures, together with some descriptive statistics, is in Appendix 1.

Second, in order to reply to critique (3), direct measures of detected tax evasion are included among the factors (positively) correlated with the amount of irregular transactions settled in cash. In this way, we remove the need to identify a set of variables that can adequately capture all the relevant determinants of shadow economy besides the level of tax burden, which is the key variable in the classic Tanzi-approach. Other factors (like, for instance, market regulation and tax morale) may indeed affect the decisions of noncompliance (see, e.g., Ferwerda et al., 2010; Schneider, 2010a, 2011; Buehn and Schneider, 2012). Looking directly at the final outcome of this process, we can circumvent the problem of an incomplete specification of the model resulting in biased estimates. Notice that the choice of considering detected evasion also shifts the interpretation of the model from a causal approach to a more simple decomposition exercise: in the traditional CDA, a higher tax burden causes a higher tax evasion; in our re-interpretation, a higher detected evasion would be simply associated with larger withdrawals of cash.

Finally, with reference again to criticism (3) and the issue of model misspecification, we argue that shadow economy accounts for just one component of the total amount of cash payments. Indeed, according to OECD (2002) classification, the activities contributing most to the socalled non-observed (cash-settled) economy in developed countries include both underground and illegal production: the former is defined as «those activities that are productive and legal but are deliberately concealed from the public authorities to avoid payment of taxes or complying with regulations», while the latter mainly refers to «the production of goods and services whose production, sale or mere possession is forbidden by law». Hence, in order to avoid potential distortions in the estimation of the underground component of non-observed economy, the reinterpretation we propose also controls for the presence of illegal production. We consider, in particular, two criminal activities like drug dealing and prostitution, which represent illegal transactions typically regulated in cash and are classified by almost all scholars among the most important activities making up the illegal economy. Notice that the choices of the individuals operating in the two sectors of non-observed economy (underground and illegal production) depend on different motivations and incentive mechanisms, including the role 
played by deterrence actions. The two components also differ remarkably for their effects on public finances and the implications in terms of law enforcement policies, since it is possible to identify potential revenues to be recovered through tax audits only for shadow economy, while in the case of illegal production the goal is to suppress the criminal activity by relying on policing and imprisonment. Despite these relevant differences, the decomposition of total nonobserved economy into underground and illegal production is an issue rarely investigated in the literature, mainly because of the difficulty in delineating the boundaries of the analysis and the lack of reliable information. Here we exploit crime indicators related to drug dealing and prostitution, with the purpose to provide a more precise estimate of the excess demand of cash transactions due to tax evasion, by disentangling the illegal component of non-observed economy and thus introducing a third innovation with respect to the traditional CDA.

\section{An application of the 'modified CDA': theoretical framework}

Our assessment of the size of the shadow economy is based on the estimation of a model of demand for cash payments where the dependent variable is a direct measure of the value of transactions at the provincial level. In particular, the dependent variable in the estimated equation is the ratio of the value of cash withdrawn from bank accounts to the value of total payments settled by instruments other than cash $(C A S H)$. This represents a measure of the demand for untraced payments per euro of traceable ones (i.e., payments settled by bank transfers, cheques, credit cards).

In line with the discussion in Section 2, we classify the determinants of CASH in three groups, thus identifying three components of the demand for cash payments: the structural component, the underground (or tax evasion) component, and the illegal (or crime) component. In the following - in line with, e.g., Torgler and Schneider (2009), Buehn and Schneider (2012) - we present our methodological approach by formulating testable hypotheses on the variables affecting each of the three mentioned components. Appendix 2 reports descriptive statistics for all covariates and information on data sources (see Tables A2 and A3).

\subsection{The structural component of the demand for cash payments}

We identify four factors related to the structural demand for cash payments: the degree of local socio-economic development; the degree of spatial diffusion of banking activities; the technology of payments; and the interest rate. 
The level of development of the economy is measured by per capita GDP at the provincial level (YPC). As suggested by several studies on shadow economy (e.g., Schneider and Enste, 2000; Schneider, 2011; Buehn and Schneider, 2012), per capita GDP has a negative expected impact on the use of cash: the higher the average living standard, the lower is the use of cash for payments (and the higher the demand for alternative payment instruments). The average income is highly correlated with education level (both general education and "financial literacy"), and more education usually leads to a lower use of cash, since more educated individuals show greater confidence in alternative payment instruments (World Bank, 2005; Ferwerda et al., 2010). Accordingly, the related hypothesis to be tested is the following.

H1: The higher the average per capita income in a province, the lower is the structural (legal) demand for cash payments, ceteris paribus.

We also consider the rate of unemployment at the provincial level (URATE) as a second possible indicator for the level of economic development. ${ }^{7}$ In particular, to some extent this variable reflects differences in income distribution (see, e.g., Brandolini et al., 2004), thus in educational levels, and is expected to exert a positive impact on the use of cash for payments. For a given average value of per capita GDP, a higher unemployment rate corresponds to a more concentrated distribution of income favouring the rich, hence with a larger share of lowincome (and poorly educated) people relying on the use of cash for their payments. We then formulate the following hypothesis:

H2: The higher the unemployment rate of a province, the higher is the structural (legal) demand for cash payments, ceteris paribus.

The number of per capita bank accounts $(B A N K)$ is included in the estimated equation as a proxy of the spatial diffusion of banking activities, thus controlling for the structural impact of the degree of bank branches concentration in provincial economies on the demand for cash payments. The expected sign of $B A N K$ coefficient is negative, as a higher presence of current accounts reduces the need to withdraw cash from ATMs for payments. Thus, the hypothesis to be tested is the following:

H3: The higher the presence of banking activities in a province, the lower is the structural (legal) demand for cash payments, ceteris paribus.

Several studies (e.g., Drehmann and Goodhart, 2000; Goodhart and Krueger, 2001; Schneider, 2009) emphasize the importance of the technology of payments, with a particular reference to

\footnotetext{
${ }^{7}$ We acknowledge an anonymous referee for pointing out this additional control.
} 
the supply of electronic instruments. We account for available technology by including the variable ELECTRO among the structural determinants of CASH. This measures the ratio of the value of transactions settled by electronic payments to provincial GDP. Since a higher share of electronic transactions (via POS and internet banking) implies a lower number of cash transactions, the expected sign of the ELECTRO coefficient is negative. Thus, we put forward the following hypothesis:

H4: The higher the diffusion of electronic payments in commercial transactions, the lower is the structural (legal) demand for cash payments, ceteris paribus.

The interest rate on bank deposits $(I N T)$ is the fourth factor of the structural component of $C A S H$. Based on standard economic theory, the interest rate is expected to have a negative effect on the demand for money, via its role of opportunity cost of holding cash in alternative to interest-bearing assets. Notice, however, that our model deals with cash flows rather than stocks of liquid assets, which implies an ambiguous effect of the interest rate. ${ }^{8}$ Higher interest rates might even have a positive impact on flows, for instance, by pushing towards forms of cash raising alternative to the banking channel. However, due to the usual 'speculative' motive, we can not exclude that the interest rate on bank deposits may also negatively affect the propensity to withdraw cash in alternative to the use of other payment instruments. Thus, the expected sign of the INT coefficient is a priori unclear and we do not formulate testable hypothesis.

\subsection{The underground component of the demand for cash payments}

We reinterpret the traditional CDA by considering measures of detected tax evasion instead of the variables usually adopted as proxies for the tax burden level, like the average income tax rate. Information on detected tax evasion are retrieved from a dataset concerning inspection activities with law enforcement purposes by the Guardia di Finanza (the Italian tax police). The availability of such information is particularly relevant for two reasons. First, as already discussed above, many factors - beyond the burden of taxes and social security contributions are likely to influence the decision to escape Tax Authorities (market regulation, tax morale of citizens, efficiency of public administration, etc.), and each of these factors would need a proper

\footnotetext{
${ }^{8}$ Several studies investigating the role of innovative payment systems in cash demand of Italian families (e.g., Ardizzi and Tresoldi, 2003; Lippi and Secchi, 2008; Alvarez and Lippi, 2009) point out that the progress in transaction technology may substantially reduce (or even eliminate) the impact of interest rate on cash demand of buyers.
} 
proxy. ${ }^{9}$ Second, tax rates might be subject to a reverse causality argument: for a given amount of public spending, in a country with a higher tax evasion, statutory tax rates need to be set at an higher level to keep the budget balanced (see, e.g., Breusch, 2005a, b). Third, to explore withincountry variations in the shadow economy, one needs specific tax rates for each sub-area, which can be difficult to obtain in presence of even a minimal degree of tax decentralization and a number of layers of government. For instance, this is the case in Italy, where there are no data on the actual tax rate at the provincial level, and the calculation of some proxies for "fiscal pressure" is not a trivial task, since taxes are levied by different levels of government (including municipalities, provinces and regions) on very different tax bases.

In order to overcome these problems, we selected two variables that provide a direct measure of the diffusion of the productive activities (partially or totally) unknown to Tax Authorities at the provincial level. $E V A S 1$ is defined by the number of specific tax audits ${ }^{10}$ in a given province divided by its sample mean (this is a measure of tax evasion intensity at the provincial level), and then weighed by a GDP concentration index. ${ }^{11}$ This latter standardization allows us to compare provinces characterized by remarkable differences in the level of economic development, thus avoiding attaching automatically higher levels of tax evasion to provinces with a number of audits above the sample mean.

The second variable (EVAS2) accounts for irregularities detected by the Guardia di Finanza during inspections to retailers. EVAS2 is computed as the ratio of the number of positive audits on cash registers and tax receipts to the number of existing POS in the province. ${ }^{12}$ The standardization for the number of POS is made necessary by the high variability in the presence of POS across provinces, which is likely to affect the opportunity to evade. ${ }^{13}$ The inclusion of both EVAS1 and EVAS2 in our model is motivated by the fact that the former refers to

\footnotetext{
${ }^{9}$ For a discussion on the determinants of the decision to participate in the shadow economy, besides tax burden, see, among others, Friedman et al. (2000), Schneider and Enste (2000, 2002), Feld and Frey (2007), Dreher et al. (2009), Torgler and Schneider (2009), Dreher and Schneider (2010), Schneider (2010a) and Buehn and Schneider (2012).

10 These audits are specific in the sense that they imply inspections to firms based on ex-ante information about frauds that occurred within a particular operation (e.g., payment of salaries) and/or are related to a single item of the tax base (e.g., income taxes or social security contributions).

11 The GDP concentration index is defined as the ratio of provincial GDP to its sample mean value.

12 Here positive stands for audits with detected evasion. The ratio is weighed for the GDP concentration index for the same reasons discussed above.

13 The availability of POS can significantly affect the likelihood to evade taxes. Retailers are obliged to accept a payment with a credit/debit card when a customer exhibits one and a POS is available, and this makes more difficult to evade taxes because the payment is traced. Thus, dividing the number of positive tax audits by the number of POS in the province allows us to weight the detected irregularities for the actual opportunities to evade (smaller where the number of POS is higher), and to obtain a more precise indicator of the diffusion of evasion: for a given number of POS, the higher the number of positive tax audits, the greater will be the underlying propensity to adopt non-compliant behaviours.
} 
inspections which may relate to any assumed fiscal irregularity (evasion of income and indirect taxes or social security contributions) in any type of business, while the latter certainly detects only tax frauds in sales by retailers (VAT and income tax evasion). Thus, EVAS1 and EVAS2 are expected to jointly provide a more comprehensive evaluation of the underground component in the demand for cash payments. Thus, the hypothesis to be tested is the following:

H5: The higher the value of EVAS1 and EVAS2, the higher is the demand for cash payments in the shadow economy, ceteris paribus.

\subsection{The illegal component of the demand for cash payments}

An index of crime diffusion (CRIME) is included as a further innovation compared to the traditional CDA, in order to separate the illegal component of non-observed (cash-settled) economy from shadow production ${ }^{14}$. CRIME is defined as the share of crimes violating the laws on drugs and prostitution over the total number of reported crimes in each province. In analogy with tax evasion variables, also this indicator has been weighted by a GDP concentration index. The normalization for the total number of crimes accounts for differences in crime specialization across provinces, which affect the use of cash: a province where we observe only crimes involving the use of cash is different from a province where crime is widespread, but only a small fraction of these crimes are related to the use of cash. The standardization using GDP is instead able to account for differences in the enforcement activity (hence, in detected crimes), which are reasonably guided by the level of economic development.

The selection of variables to estimate the size of the illegal production deserves a brief explanation. Our choice of drug- and prostitution-related offenses is motivated by the focus on criminal activities that - in line with the OECD (2002) definition of illegal economy discussed above - imply an exchange between a seller and a buyer relying on a mutual agreement and a voluntary cash payment. Therefore, we excluded all those crimes which, to some extent, are based on the use of violence made to persons or properties (burglary, extortion, etc), and then imply 'transfers of money' which do not follow an 'agreement' between the thief, for instance, and the victim. ${ }^{15}$ We also excluded those offences with possible ambiguous effects on the size of

\footnotetext{
14 To the best of our knowledge, the unique previous attempt to account for the presence of criminal activities in the Italian context is provided by Zizza (2002). However, for the reasons discussed here, the crime indicator used in Zizza (2002) is inadequate to capture the excess demand for cash payments due to illegal production.

${ }^{15}$ We do not account for money laundering in our analysis, since this is a criminal offense which results from other underlying criminal activities that amplifies in a cumulative way the impact of organized crime on both regular and irregular economies. The definition of recycling implies that the income stemming from a crime needs to be 'cleaned up' through the legal channel (e.g., bank transactions) in order to lower the likelihood for the criminal
} 
cash withdrawals. This is, for instance, the case of thefts, which could also have a negative impact on $C A S H$ due to the fact that - in areas where more robberies occur - individuals will find too dangerous to hold money in cash. In essence, our choice is consistent with the model to be estimated, which exploits information on cash withdrawals from bank accounts due to a voluntary transactional motive. The hypothesis to be tested is then:

H6: The higher the value of CRIME, the higher is the demand for cash payments in the illegal economy, ceteris paribus.

\subsection{The complete 'modified CDA' model}

Equation [1] sums up the previous theoretical discussion, providing the complete model of the demand for cash payments to be estimated. We consider the three groups of variables discussed above, identifying the structural demand for cash reflecting the ordinary preference for liquidity, augmented by the two components related to the underground economy and the illegal production:

$$
\begin{aligned}
& C A S H_{i t}=\breve{U}_{0}+\breve{U}_{1} Y P C_{i t}+\breve{U}_{2} U R A T E_{i t}+\breve{U}_{3} B A N K_{i t}+\breve{U}_{4} E L E C T R O_{i t}+\breve{U}_{5} I N T_{i t} \\
& +\breve{U}_{6} E V A S 1_{i t}+\breve{U}_{7} E V A S 2_{i t}+\breve{U}_{8} C R I M E_{i t}+\varepsilon_{i t}
\end{aligned}
$$

Once obtained the parameter estimates of the model, we adapt and apply the original procedure proposed by Tanzi (1983) for the assessment of the underground economy. The size of the total (shadow plus illegal) non-observed production is given by the 'excess demand' for cash payments unexplained by structural factors. This excess demand is obtained as the difference between the fitted values of $C A S H$ from the full model [1], and predicted values obtained from a restricted version of Equation [1] setting $E V A S 1=E V A S 2=C R I M E=0$. To evaluate separately the size of the two components of the non-observed economy, we then proceed in a similar manner, by imposing alternatively the restrictions $E V A S 1=E V A S 2=0$ and $C R I M E$ $=0$, and calculating the excess demand for cash payments due to tax evasion (underground production) and criminal activities (illegal production), respectively. Given our definition of $C A S H$, the estimates obtained in this way are expressed in relation to total payments settled by instruments other than cash. In order to have measures comparable with previous studies, we then rescale our estimates of shadow and illegal economy, and express our results in terms of provincial GDP.

agent of being caught. After this, the 'cleaned up' money can be reinvested in legal activities (see, e.g., Schneider and Windischbauer, 2008, and Schneider, 2010b). 


\section{Econometric analysis}

\subsection{Baseline model specifications}

To illustrate our 'modified CDA', we depart from the existing literature on Italy, which has so far dealt with country-level data, and apply model [1] to a balanced panel of 91 Italian provinces observed from 2005 to 2008 . The units included in the sample represent about $90 \%$ of all the Italian provinces (103), and are those for which complete information were available for all the variables included in Equation [1].

Given the panel structure of the database and the distribution of our dependent variable, we use a Random Effects Tobit model to account for unobserved residual heterogeneity across provinces. This model has the advantage - as compared to a standard panel regression with individual random effects - to accommodate for the particular distribution of the dependent variable, which is censored at zero and can assume only positive values ${ }^{16}$. In particular, we specify the error structure of Equation [1] as $\stackrel{\circ}{t}_{t}=u_{\mathrm{i}}+e_{i t}$, where $u$ and $e$ are provincial effects and the standard disturbance term, respectively.

Our baseline specifications are in Table 1. With respect to Equation [1], MODEL A and B do not consider the unemployment rate, which is included in models $\mathrm{C}$ and D. More important, MODEL A and $\mathrm{C}$ accounts only for the underground production as a component of the non-observed economy, while MODEL B and D consider both tax evasion and criminal activities, including the variable CRIME. Estimates are pretty much consistent across the four specifications, and coefficients show up the expected signs and are statistically significant at the usual confidence levels. For all the four specifications, the coefficient $f-$ which measures the proportion of total residual variance explained by individual effects $(u)$ in relation to the proportion explained by noise $(e)-$ is about 0.80 , highlighting the importance of using panel techniques, in order to control for the presence of unobserved heterogeneity due to provincial-specific idiosyncratic random shocks.

The inclusion of URATE as a further control for the structural demand for cash reduces the magnitude of the per capita GDP, taking up a positive sign. As expected, the unemployment rate also interacts with the components of the underground economy (especially with the activity of retailers, which often make use of irregular workers), allowing for a better identification of the contribution of each to the demand for cash. In particular, while the

\footnotetext{
${ }^{16}$ See, e.g., Wooldridge (2002). Notice that the theoretical distribution of $C A S H$ is between 0 , if all transactions are carried out using payment methods different from cash, to infinity, if all transactions are carried out using cash.
} 
magnitude of the coefficient for $E V A S 1$ is substantially unchanged when including $U R A T E$ in the model, $E V A S 2$ increases from 0.010 to 0.018 (MODEL B vs. MODEL D).

Moreover, estimates in Table 1 confirms the importance of controlling for the presence of illegal activities (drug dealing and prostitution) in order to correctly assess the extent of the underground economy. In fact, as suggested by LR tests (MODEL A vs. MODEL D, p-value = 0.002; MODEL C vs. MODEL D, p-value $=0.003)$, the inclusion of CRIME significantly improves the goodness of fit of the model. It also reduces the magnitude of the coefficients associated to EVAS2 (especially when we do not account for $U R A T E, \alpha_{7}=0.027$ vs. 0.010) and $E V A S 1$ (when URATE is included, $\alpha_{6}=0.009$ vs. 0.006), thus lowering the total impact of tax evasion on the demand for cash and, eventually, the estimated size of the shadow production. Interestingly, considering illegal activities also impacts on the structural component of the demand for cash, reducing coefficients for YPC and URATE, and doubling the one of $B A N K$. Though discomforting, a likely interpretation is that the level of economic development could be (positively) associated to the demand of 'criminal services'.

Before moving further notice that the pattern of these results is broadly confirmed when substituting the Tobit model with an alternative Random Effects GLS specification, allowing for robust standard errors clustered at the provincial level (see Appendix 2, Table A4). Hence, one might expect that also the size of the non-observed economy will not be affected by the choice of a particular model to estimate the demand for cash.

[Table 1 about here]

Table 2 provides the average size of the non-observed economy derived from all the four models in Table 1. The values has been obtained by first computing for each province in each year separate measures for the underground economy and the illegal production (when possible), and then identifying outliers using the Hadi (1992, 1994) method before calculating the averages. Interesting results emerge from the table. First, our estimates emphasise the need to control for cash used in criminal transactions in order to obtain a better representation of the underground economy. Indeed, when controlling also for criminal activities as a component of the demand for cash, the estimated size of the non-observed economy due to tax evasion (between $16.5 \%$ and $17.5 \%$ of GDP over the entire period 2005-2008) is very close to the official figures provided by the Italian National Institute of Statistics (Istat, 2010), while, e.g., Schneider and Enste (2000, 2002) and Buehn and Schneider (2012) report much higher values (above 25\% from mid-90s 
until 2000 and stably around 27\% from 2000 until 2007). As already suggested by Zizza (2002), this discrepancy is likely to be attributable to the role played by criminal activities. Indeed, the ratio of the illegal production 'value added' to GDP in 2007 is in line with the only available estimates provided by Eurispes (2008) for the same year (about 11\% of GDP). The estimates of MODEL A and $\mathrm{C}$ - where the crime indicator is not included - confirms that neglecting the component of illegal economy in the application of the CDA leads to an overestimation of the underground production. For instance, MODEL $\mathrm{C}$ implies a higher value of the underground economy than MODEL $D, 26.1 \%$ vs. $17.5 \%$ on average in $2005-2008$. Notice that this value is also slightly lower than the sum of the shadow economy and the illegal production estimated in MODEL D (27.5\%). Hence, ignoring crime as a component of total cash payments brings about two possible measurement errors: on the one side, it muddles up tax evasion and illegal production; on the other side, it brings to underestimate the total size of the non-observed economy. Notice that these results hold even when using the Random Effects GLS model (Table 3). Looking at the more complete MODEL D, the estimated average size of the total non-observed economy is $28.6 \%$ of GDP in $2005-2008$, which is pretty close to estimates obtained with the Tobit model (27.5\%). Also the decomposition is similar: in both cases, about $1 / 3$ is attributable to crime, and the remaining $2 / 3$ make up the underground economy.

Second, confirming previous studies (e.g., Loayza and Rigolini, 2011, Fiess et al., 2010), the temporal dynamics of both components for all the four models suggests a link between nonobserved economy and the economic cycle. For instance, considering the more complete MODEL D in Table 2, one can observe an increasing trend from 2005 to 2008 for both components, although the increase appears more marked for tax evasion $(+5.1 \%)$ than for the criminal economy $(+2.3 \%)$, with a sharp jump in the transition from 2006 to $2007(+3.4 \%$ and $+1.5 \%$, respectively). Again, also these trends are confirmed when estimating the demand for cash with a Random Effects GLS model: from Table 3, the increase for tax evasion $(+4.2 \%)$ is larger than for the illegal component of the demand for money $(+2.1 \%)$, with much of the variation concentrated between 2006 and 2007. Such evidence may be, at least in part, due to the fact that the Italian economy in 2007 , like other countries in the euro zone, began to suffer the cyclical downturn caused by the severe world financial crisis, with a sharp slowdown in consumptions and investments and a strong deterioration in firms' trust indicators (Bank of Italy, 2007). The negative expectations of the operators may then have led to an increased 
subtraction of taxable income to Fiscal Authorities, and a more marked use of the black labour market, and/or even to turn to illegal sectors of the economy (e.g., prostitution, drug dealing). ${ }^{17}$ The anti-cyclical behaviour of the non-observed economy might suggest a change in the relationship between structural variables, the indicators for underground economy and crime, and the demand for cash. We then checked the stability of the parameters in our model by defining the dummy variable $T 2$ equal to 1 for the years 2007-2008, and interacting this dummy with all the variables included in Equation [1]. The estimates of this augmented model (using both the Tobit and GLS specifications) are in Table A5 in Appendix 2. All the interactions and the coefficient for $T 2$ itself turn out to be statistically insignificant. Unsurprisingly, a Wald test for the hypothesis that all interactions and the $T 2$ coefficient are jointly insignificant does not reject the null. ${ }^{18}$ We then take the more complete MODEL D and the derived estimates of the non-observed economy as our baseline results, and check their robustness in a number of directions in what follows.

[Tables 2 and 3 about here]

\subsection{Robustness checks}

In this section we consider three robustness checks for our findings. A first robustness check is related to the clustering of illegal activities in certain areas. In particular, a well-known stylized fact is that crime rates are higher in large cities than in other urban contexts. One explanation of why it is so - pointed out by Glaeser and Sacerdote (1999) - is that pecuniary benefits for crime are larger in large cities as compared to small cities or rural villages. One may then wonder how robust our results are to the presence in our sample of provinces characterized by large urban centers, like Rome or Milan, with 2.7 million and 1.3 million citizens respectively. To test for this we use jackknifing, and re-estimate the more complete MODEL D both with the Random Effects Tobit specification and the Random Effects GLS specification, leaving out from the sample three subsets of observations: subset 1 considers the three provinces with the largest cities in the Centre-North (Rome, Milan and Turin); subset 2 considers the three

\footnotetext{
17 Notice that these changes in the economic cycle involve likely variations in the velocity of money, which presumably fell in the official economy and increased in the irregular sectors. This further supports the adoption of an estimation approach - such as the 'modified CDA' proposed here - that overcomes the restriction of the velocity of money constant over time and identical between regular and non-observed economy.

${ }^{18}$ The p-value of the $\chi^{2}$ statistic is 0.170 in the Random Effects Tobit model and 0.153 in the Random Effects GLS model.
} 
provinces with the largest cities in the South (Bari, Naples and Palermo); subset 3 considers jointly the two previous groups. Estimates of these models are in Tables A6-A8 in Appendix 2. The signs, the magnitudes, and the statistical significance of almost all coefficients are largely confirmed. We only observe some minor changes in the magnitudes for coefficients of $Y P C$, URATE and EVAS2 when excluding from the sample the three Southern provinces. In particular, the (negative) impact of income becomes larger, while that of unemployment and that of tax frauds in sales by retailers approximately halve, likely because these three Southern provinces are also those with the highest per capita income within the Southern regions. More important, estimates of the size of non-observed economy and the relative weights of the underground economy and the illegal production are also broadly confirmed. For instance, from Table 4, considering the Tobit specification, the average size of non-observed economy to be compared with the initial estimates of $27.5 \%$ in MODEL D is: $28 \%$ excluding the three CenterNorth provinces; $27.6 \%$ excluding those in the South; $28.4 \%$ excluding both.

\section{[Table 4 about here]}

A second issue that might threaten the robustness of our findings is the use of GDP concentration index to standardize our indicators of tax evasion EVASI and EVAS2 and the indicator for criminal activities CRIME. While the standardization itself is needed to compare provinces characterized by remarkable differences in the level of economic development (which can then imply a higher number of audits and inspections to fight crime in the richer areas), the use of income can bias the estimates since it is directly related to the use of cash and - more important - it includes an estimate of the shadow economy (Istat, 2010). We then re-estimate our previous MODEL D standardizing EVAS1, EVAS2 and CRIME with an employment concentration index, which accounts for differences in economic development but it does not suffer the two drawbacks mentioned before. Estimates of this new model, both with the Tobit and GLS specifications, are in Table A9 in Appendix 2. As before, the signs, the magnitudes, and the statistical significance of almost all coefficients are basically confirmed. From Table 5, also the size and the evolution of the non-observed economy, and the relative weights of underground and illegal production, are broadly similar to our baseline estimates. Considering the Tobit specification, the average total non-observed economy is now $30.9 \%$ of GDP (compared to $27.5 \%$ obtained from MODEL D in Table 1), of which $19.7 \%$ is related to the 
underground economy and the remaining $11.2 \%$ is related to criminal dealings. ${ }^{19} \mathrm{We}$ also observe the large jump between 2006 and 2007 discussed above, which probably reflects the impact of the cyclical downturn.

[Table 5 about here]

Finally, we also check whether our findings are robust to splitting the variable $C R I M E$ in its two components, drug $(D R U G)$ and prostitution (PROST). Estimates of this additional model, considering both Tobit and GLS specifications, are in Table A10 in Appendix 2. Drug related offences appear to be the criminal activity driving the results, with a coefficient statistically significant and approximately the same magnitude of $C R I M E$ in our baseline model. On the contrary, coefficient for PROST picks up the expected positive sign, but it is not statistically significant at the usual confidence levels. ${ }^{20}$ Estimates of the size of the non-observed economy from this additional model are in Table 6, and pretty much confirm previous findings. Considering the Tobit model, the underground economy makes up on average $16.9 \%$ of provincial GDP. As for the illegal production, drug trafficking is estimated to generate demand for cash equivalent to $8.4 \%$ of GDP, while prostitution generates only a mere $1.6 \%$. The total estimated size of the non-observed economy is $26.9 \%$, quite close to the baseline estimate of $27.5 \%$ of GDP.

[Table 6 about here]

\subsection{Within-country disaggregated estimates}

In this section we look at disaggregated territorial estimates of the two components of the nonobserved economy, a particularly interesting issue for the Italian case in the light of the marked regional differentials in the distribution of tax bases and in the concentration of the organized crime. At least two questions deserve to be explored: first, given the higher degree of economic

\footnotetext{
${ }^{19}$ It is worth noticing that the slightly higher values obtained for the two components of non-observed economy are likely to be the results of the lower variability in the sample of the number of employed people out of the total population compared to GDP per capita (the coefficient of variation is 0.14 for the former variable against 0.24 for the latter). This difference reflects the fact that the employment index, differently from GDP, does not reflect the variation in the nominal value of production due to the variation in input prices - especially in wages and between centre-northern and southern provinces - hence implying a less precise correction of our indicators of detected tax evasion and crime for the differences observed in the level of economic development across provinces.

${ }^{20}$ As shown in Table A3 in Appendix 2, this result can be attributed to the fact that - compared to DRUGPROST accounts for a minor share of total crime index (CRIME) and presents a low variability in the sample.
} 
and industrial development of the Central-Northern provinces with respect to Southern ones, does the size of the underground production differ between the North and the South of the country? Second, does the prevalent localization of the 'headquarters' of criminal organizations in the South of Italy imply a higher contribution of the Southern regions to the formation of the illegal component of the non-observed economy? Or, instead, is it reasonable to expect minor territorial differences, due to the high mobility of criminal resources?

According to results reported in Table 7, which are derived from estimates of MODEL D in Table 1 and Table A4, compared to Southern provinces, those in the Centre-North exhibit a higher incidence of the non-observed economy on GDP. More important, this larger size is due both to a larger tax evasion (19\% vs. 14\%) and to a larger weight of criminal activities (11.5\% vs. $6.7 \%$ ). The finding is robust to the choice of the econometric specification (Table 7, Random Effects GLS), but also to the use of jackknifing and the exclusion from the sample of the provinces with the largest cities in terms of citizens (Table 8). Interestingly, excluding the three provinces with the largest Southern cities from the sample brings about a reduction in the relative weight of the underground economy, and an increase in the size of illegal production. The implication seems to be that - in these Southern provinces - the non-observed economy is much more related to the underground production than to criminal activities. We also confirm, in Table 9, that the illegal production is mainly due to drug trafficking, which accounts for 9.6\% of GDP in Centre-Northern provinces and 5.9\% in Southern ones, as compared to $2 \%$ and $0.9 \%$, respectively, for prostitution.

[Tables 7, 8 and 9 about here]

Despite being against the widespread opinion about the presence of a higher shadow economy and illegal production in the South of the country ${ }^{21}$, such an evidence of a significant gap between Centre-North and South supports the results obtained by the few previous studies based on alternative estimation methodologies. Relying on time series data from the early ' $80 \mathrm{~s}$ to the late ' $90 \mathrm{~s}$, Bovi et al. (2002) estimate a higher tax evasion in the North than in the South in several years. More recently, looking at more specific taxes (the Personal Income Tax

\footnotetext{
21 This opinion largely relies on the fact that in Southern regions payments are settled by instruments other than cash to a lower extent than in the Centre-North. The descriptive statistics reported in Table A3 in Appendix 2 clearly show that the use of cash is higher in the South than in the rest of the country (the mean values of $C A S H$ are 0.09 and 0.15 in the Centre-North and in the South, respectively). However, far from being in contrast with our results, these statistics provide evidence that in less advanced regions, because of the lower degree of financial development, a higher share of transactions in the official economy are settled in cash.
} 
IRPEF, and a tax on productive activities IRAP), Marino and Zizza (2008) and Pisani and Polito (2006) both conclude that in many cases tax evasion is higher in the Centre-North than in the rest of the country. The results delivered in 2011 by the Working Group Economia non osservata e flussi finanziari (literally, 'Non-observed economy and financial flows') - established by the Ministry of Economy and chaired by the President of the Italian Statistical Office - go in the same direction. Finally, a recent survey by one of the three biggest unions shows the significant increase in the diffusion of irregular workers in the Northern regions (UIL, 2011). As for the illegal component of the non-observed economy, the higher incidence observed for the Centre-North is probably justified by the fact that the use of cash for transactions related to criminal activities is higher where the 'retail markets' for goods and services such as drug and prostitution are more lucrative. Hence, despite criminal organizations having their 'headquarters' predominantly localized in the South, our evidence seems to suggest their ability to export illegal activities in the richest areas of the country. ${ }^{22}$

Finally, as Figure 1 makes clear, notice that macro-area averages hide significant differences across provinces. It is clear that the size of non-observed economy is smaller in Southern provinces than in Centre-Northern ones. But the underground and the illegal production follow clustering patterns which are difficult to rationalize at first sight. A likely explanation is that these patterns are probably linked to geographical flows of people and goods across provinces in different regions. The likely presence of these flows suggests a potential drawback of using disaggregated estimates at the provincial level instead of macro-area averages, i.e., the possibility that money has been withdrawn in one province to be spent in another one, or even abroad.

\section{Conclusions}

In this paper we contribute to the debate on assessing the size of the underground economy by providing a reinterpretation of the CDA à la Tanzi, which aims at overcoming its most relevant weaknesses as remarked in Scheider and Enste $(2000,2002)$. Our main contributions can be summarized as follows. First, we introduce a direct measure of the value of cash transactions as the dependent variable in the money demand equation. In particular, we use the flow of cash withdrawn from bank accounts with respect to total noncash payments in substitution of the traditional money stock variable. This departure from the standard CDA makes it possible to avoid the unrealistic assumptions of the absence of underground production in a given base

22 The ability of criminal organizations to 'export' their businesses is discussed, e.g., in Varese (2011). 
year, and of a common velocity of money in the official economy and the irregular sector. Second, instead of considering a causal model in which the tax burden is the main determinant of the decision to operate in the underground economy, we disentangle the 'excess demand' for cash payments due to tax evasion by exploiting direct information on detected non-compliance, thus overcoming the problem of finding suitable proxies able to capture all the relevant causes of the phenomenon. Third, we control also for the role played by illegal production (considering crimes like drug dealing and prostitution), which - jointly with the shadow economy contributes to the larger aggregate of the non-observed economy and represents a significant component of total cash payments.

We present an application of this 'modified CDA' exploiting original data on monetary variables, tax evasion and reported illegal activities for the Italian Provinces over the period 2005-2008. Our baseline results show an average value of the shadow economy of $17.5 \%$ of GDP, which is consistent with the recent estimates available from official statistical sources relying on microeconomic methods of measurement, but appears lower than the values obtained for Italy in the international literature (e.g., Schneider and Enste, 2000, 2002 and Buehn and Schneider, 2012). We show that this discrepancy is likely to be due to the omission of illegal activities in the application of the traditional CDA à la Tanzi. Not surprisingly, when the model does not account for the role played by criminal transactions, which amount, on average, to about $10 \%$ of GDP, our estimate of the underground economy increases up to $26.1 \%$ of GDP. This evidence is robust to a number of controls which includes: alternative econometric specifications; the use of jackknifing and the exclusion from the sample of those provinces with the largest cities; the use of different weights to take into account differences in economic development, which presumably drive both tax enforcement and law enforcement activities; the definition of the crime indicators. A general conclusion stemming from our findings is that, ignoring illegal production, one could not only mistakenly attribute to shadow economy the part of cash payments due to criminal transactions - for which it is not possible to implement enforcement policies in order to recover lost tax revenues - but also underestimate the total incidence of the non-observed economy (i.e., underground plus illegal production).

Given the availability of relevant information at a disaggregated territorial level, we also provide estimates of the shadow and illegal economy by macro-areas. This is an important step in the understanding of the non-observed economy and its size, because of the marked NorthSouth divide in the level of economic development, institutional quality and social capital in Italy. The evidence we provide suggests that, compared to Southern provinces, those in the 
Centre-North exhibit a higher incidence of both underground economy and illegal production relative to GDP. While the result on crime is likely to be related to the ability of criminal organizations to 'export' illegal activities in the retail markets of the richest areas of the country, where demand of drugs and prostitution is presumably higher, the findings concerning tax compliance and the clustering of underground production in neighbouring provinces stimulate further research on the determinants of this higher propensity to evade in the richest Northern part of the country.

As for the policy implications directed at reducing the size of the non-observed economy that can be drawn from our results, the general suggestion will be the introduction of measures that make cash more difficult and more costly to use relative to other instruments. Since we observe a positive correlation between the use of cash and the non-observed economy, limiting the use of cash is likely to limit also the non-observed economy. A measure recently undertaken by the Italian government goes exactly in this direction: it provides an upper limit of 1,000 euro for the value of cash transactions, and makes compulsory the use of traceable payment methods for all transaction above this threshold (see the article 12 of the Law 201/2011, the so-called Law "Salva Italia"). A second (somewhat provoking) measure discussed in the political debate is the proposal to tax both withdrawals and deposits of cash over a certain threshold. However, the tax rate should be high enough to outweigh the economic advantages deriving from tax evasion and illegal activities in order to reach the proposed goal of reducing the size of the non-observed economy. As the interests at stake are high, the tax will reasonably remain just a proposal. Finally, a third group of measures is directed at favouring the use of instruments alternative to cash: these include, for instance, incentives for the diffusion of electronic payments, as well as public campaigns aimed at modifying the cultural bias toward the use of cash, especially in certain areas of the country. It could be difficult, but it seems worth it. 


\section{References}

Ahumada, H., Alvaredo, F. and Canavese, A. (2007), "The Monetary Method and the Size of the Shadow Economy: A Critical Assessment", Review of Income and Wealth, 53(2), 363-371.

Ahumada, H., Alvaredo, F., \& Canavese, A. (2008), "The monetary method to measure the shadow economy: The forgotten problem of the initial conditions", Economics Letters, 101, 97-99.

Alvarez, F. and Lippi, F. (2009), "Financial Innovation and the Transactions Demand for Cash", Econometrica, 77(2), 363-402.

Ardizzi, G. and Tresoldi, C. (2003), "Spunti di riflessione sull'uso del contante nei pagamenti", Banca Impresa Società, 2, 153-188.

Bank of Italy (2007), Relazione Annuale, Rome.

Bank of Italy (various years), Survey on Household Income and Wealth, Rome.

Bovi, M., Hermann, A., Pappalardo, C. and Sica, F. (2002), "Il sommerso: cause, intensità territoriali, politiche di regolarizzazione", in ISAE (a cura di), Rapporto Trimestrale Priorità nazionali: trasparenza, flessibilità, opportunità, n. 9, 55-100.

Brandolini, A., Cannari, L., D’Alessio, G. and Faiella, I. (2004), "Household Wealth Distribution in Italy in the 1990s", Bank of Italy, Discussion paper, No. 530, December 2004 .

Breusch, T. (2005a), “Australia's Cash Economy: Are the Estimates Credible?", The Economic Record, 81, 394-403.

Breusch, T. (2005b), Fragility of Tanzi's Method of Estimating the Underground Economy, Working Paper, School of Economics, Australian National University, Canberra.

Buehn, A. (2012), “The shadow economy in German regions: An empirical assessment”, German Economic Review, 13 (3), 275-290.

Buehn, A. and Schneider, F. (2012), "Shadow economies around the world: novel insights, accepted knowledge, and new estimates", International Tax and Public Finance, 19, 139-171.

Buehn, A., Karmann, A., and Schneider, F. (2009), "Shadow economy and do-it-yourself activities: The German case", Journal of Institutional and Theoretical Economics, 165, 701722.

Cagan, P. (1958), "The Demand for Currency Relative to Total Money Supply", Journal of Political Economy, 66, 303-328.

Dreher, A. and Schneider, F. (2010), "Corruption and the Shadow Economy: An Empirical Analysis", 144(2), Public Choice, 215-238. 
Dreher, A., Kotsogiannis, C. and McCorriston, S. (2009), "How Do Institutions Affect Corruption and the Shadow Economy?", International Tax and Public Finance, 16(4), 773796.

Drehmann, M. and Goodhart, C.A.E. (2000), Is Cash Becoming Technologically Outmoded? Or Does it Remain Necessary to Facilitate Bad Behaviour? An Empirical Investigation into the Determinants of Cash Holdings, Financial Markets Group Research Centre, Discussion Paper 358, LSE.

Eurispes (2008), Rapporto Italia 2008, Istituto di Studi Politici Economici e Sociali, Rome.

European Central Bank (2008), Economic Bulletin, special edition, May.

Feld, L. and Frey, B.S. (2007), "Tax Compliance as the Result of a Psychological Tax Contract: The Role of Incentives and Responsive Regulation", Law and Policy, 29(1), 102-120.

Ferwerda, J, Deleanu, I. and Unger, B. (2010), Revaluating the Tanzi-Model to Estimate the Underground Economy, Tjalling C. Koopmans Research Institute, Discussion Paper 10-04, Utrecht School of Economics, February.

Fiess, N. M., Fugazza, M. and Maloney, W. F. (2010), "Informal self-employment and macroeconomic fluctuations", Journal of Development Economics, 91(2), 211-226.

Frey, B, and Weck-Hanneman, H. (1984), "The Hidden Economy as an "Unobservable' variable", European Economic Review, 26(1), pp. 33-53.

Friedman, E., Johnson, S., Kaufmann, D. and Zoido-Lobatón, P. (2000), “Dodging the Grabbing Hand: The Determinants of Unofficial Activity in 69 Countries", Journal of Public Economics, 76(3), 459-493.

Giles, D. E. A. (1999), "Measuring the hidden economy: Implications for econometric modelling", Economic Journal, 109, 370-380.

Glaeser, E. L. and Sacerdote, B. (1999), Why is there more crime in cities? Journal of Political Economy, 107 (6), S225-S258.

Goodhart, C. and Krueger, M (2001), The Impact of Technology on Cash Usage, Financial Markets Group Research Centre, Discussion Paper 374, LSE.

Hadi, A.S. (1992), “Identifying Multiple Outliers in Multivariate Data”, Journal of the Royal Statistical Society, Series B, 54, 761-771.

Hadi, A.S. (1994), "A Modification of a Method for the Detection of Outliers in Multivariate Samples", Journal of the Royal Statistical Society, Series B, 56, 393-396.

Istat (2010), "La misura dell'economia sommersa secondo le statistiche ufficiali. Anni 20002008", Conti Nazionali - Statistiche in Breve, Istituto Nazionale di Statistica, Rome.

Lippi., F. and Secchi, A. (2008), Technological Change and the Demand for Currency: An Analysis with Household Data, Bank of Italy, Temi di Discussione, Nr. 697, Roma. 
Loayza, N. V. and Rigolini, J. 82011), “Informal employment: Safety net or growth engine?”, World Development, 39(9), 1503-1515.

Marino, M.R. and Zizza, R. (2008), L'evasione dell'Irpef: una stima per tipologia di contribuente, mimeo, Bank of Italy, Rome.

Mogensen, G.V., Kvist, H.K., Kormendi, E. e Pedersen, S. (1995), The Shadow Economy in Denmark 1994: Measurement and Results, Rockwool Foundation Research Unit, Study n. 3, Copenhagen.

OECD (2002), Measuring the Non-Observed Economy - A Handbook, Paris.

Pickhardt, M., and Sarda, J. (2006), "Size and scope of the underground economy in Germany", Applied Economics, 38(14), 1707-1713.

Pickhardt, M. and Sarda, J. (2011), "The Size of the Underground Economy in Germany: A Correction of the Record and New Evidence from the Modified-Cash-Deposit-Ratio Approach", European Journal of Law and Economics, 32, 143-163.

Pisani, S. and Polito, C. (2006), Analisi dell'evasione fondata sui dati IRAP - Anni 1998-2002, Ministero dell'Economia e delle Finanze, Agenzia dell'Entrate, Documenti di lavoro dell’Ufficio Studi.

Schneider, F. (2009), The Shadow Economy in Europe. Using Payment Systems to Combat the Shadow Economy, A.T. Kearney Research Report, September.

Schneider, F (2010a), "The Influence of Public Institutions on the Shadow Economy: An Empirical Investigation for OECD Countries", Review of Law and Economics, 6(3), 441-468.

Schneider, F. (2010b), "Turnover of Organized Crime and Money Laundering: Some Preliminary Empirical Findings", Public Choice, 144(3), 473-486.

Schneider, F. (2011), Handbook on the Shadow Economy, Cheltenham (UK): Edward Elgar.

Schneider, F. and Enste, D.H. (2000), "Shadow Economies: Size, Causes and Consequences", Journal of Economic Literature, 38(1), 77-114.

Schneider, F. and Enste, D.H. (2002), The Shadow Economy: Theoretical Approaches, Empirical Studies, and Political Implications, Cambridge University Press, UK.

Schneider, F. and Windischbauer, U. (2008), "Money Laundering: Some Facts", European Journal of Law and Economics, 26(3), 387-404.

Tanzi, V. (1980), "The Underground Economy in the United States: Estimates and Implications", Banca Nazionale del Lavoro Quarterly Review, 135(4), 427-453.

Tanzi, V. (1983), “The Underground Economy in the United States: Annual Estimates 19301980", IMF Staff Papers, 30(2), 283-305.

Torgler, B. and Schneider, F. (2009) "The Impact of Tax Morale and Institutional Quality on the Shadow Economy", Journal of Economic Psychology, 30(2), 228-245. 
UIL (2011), $2^{\circ}$ Rapporto UIL sul lavoro sommerso, Servizio Politiche del Lavoro e della Formazione, Rome.

Varese, F. (2011), Mafias on the Move: How Organized Crime Conquers New Territories, Princeton, Princeton University Press.

Wagstaff, A., van Doorslaer, E. and Watanabe, N. (2003), "On decomposing the causes of health sector inequalities with an application to malnutrition inequalities in Vietnam", Journal of Econometrics, 112(1), 207-223.

Wooldridge, J.M. (2002), Econometric Analysis of Cross Section and Panel Data, MIT Press, Cambridge, Massachusetts.

World Bank (2005), International Migration, Remittances, and the Brain Drain, M. Schiff and C. Ozden (eds.), Washington, D.C.

Zizza, R. (2002), Metodologie di stima dell'economia sommersa: un'applicazione al caso italiano, Bank of Italy, Temi di Discussione, Nr. 463, December. 
Table 1. Estimated demand for cash payments (Random Effects Tobit model - 91 Italian provinces, 2005-2008) a

\begin{tabular}{|c|c|c|c|c|}
\hline Regressors b & MODEL A & MODEL B & MODEL C & MODEL D \\
\hline \multirow[t]{2}{*}{$Y P C$} & $-0.030^{* * *}$ & $-0.026^{* * *}$ & $-0.023 * * *$ & $-0.017 * * *$ \\
\hline & $(0.003)$ & $(0.004)$ & $(0.004)$ & $(0.005)$ \\
\hline \multirow[t]{2}{*}{$U R A T E$} & - & - & $0.140 * * *$ & $0.091 * *$ \\
\hline & & & $(0.046)$ & $(0.044)$ \\
\hline \multirow[t]{2}{*}{$B A N K$} & $-0.037 * * *$ & $-0.061^{* * *}$ & $-0.032 * * *$ & $-0.065^{* * *}$ \\
\hline & $(0.011)$ & $(0.013)$ & $(0.010)$ & $(0.011)$ \\
\hline \multirow[t]{2}{*}{ ELECTRO } & $-0.005^{* * *}$ & $-0.005^{* * *}$ & $-0.004 * * *$ & $-0.006^{* * *}$ \\
\hline & $(0.001)$ & $(0.001)$ & $(0.001)$ & $(0.001)$ \\
\hline \multirow[t]{2}{*}{$I N T$} & $-0.011 * * *$ & $-0.010^{* * *}$ & $-0.012 * * *$ & $-0.011^{* * *}$ \\
\hline & $(0.002)$ & $(0.002)$ & $(0.002)$ & $(0.002)$ \\
\hline \multirow[t]{2}{*}{$E V A S 1$} & $0.006^{* * *}$ & $0.006^{* * *}$ & $0.009^{* * *}$ & $0.006^{* * *}$ \\
\hline & $(0.002)$ & $(0.002)$ & $(0.002)$ & $(0.002)$ \\
\hline \multirow[t]{2}{*}{$E V A S 2$} & $0.027 * * *$ & $0.010^{*}$ & $0.019^{* * *}$ & $0.018 * * *$ \\
\hline & $(0.005)$ & $(0.006)$ & $(0.005)$ & $(0.006)$ \\
\hline \multirow[t]{2}{*}{ CRIME } & - & $0.286^{* * *}$ & - & $0.262 * * *$ \\
\hline & & $(0.063)$ & & $(0.064)$ \\
\hline \multirow[t]{2}{*}{ Constant } & $0.220 * * *$ & $0.222 * * *$ & $0.182^{* * *}$ & $0.195 * * *$ \\
\hline & $(0.006)$ & $(0.006)$ & $(0.012)$ & $(0.012)$ \\
\hline Observations & 364 & 364 & 364 & 364 \\
\hline Log-likelihood & 959.08 & 963.96 & 961.26 & 965.61 \\
\hline McFadden's pseudo- $\mathbf{R}^{2}$ & 0.13 & 0.14 & 0.13 & 0.14 \\
\hline Wald statistic $\left(\chi^{2}\right)$ & $1969.51^{* * *}$ & $2563.29 * * *$ & $1700.19 * * *$ & $2413.28 * * *$ \\
\hline \multirow[t]{2}{*}{$\sigma_{u}$} & $0.022 * * *$ & $0.023^{* * *}$ & $0.026^{* * *}$ & $0.023 * * *$ \\
\hline & $(0.001)$ & $(0.001)$ & $(0.001)$ & $(0.001)$ \\
\hline \multirow[t]{2}{*}{$\sigma_{e}$} & $0.012^{* * *}$ & $0.012^{* * *}$ & $0.012^{* * *}$ & $0.012 * * *$ \\
\hline & $(0.000)$ & $(0.000)$ & $(0.000)$ & $(0.000)$ \\
\hline \multirow[t]{2}{*}{$\rho$} & 0.772 & 0.784 & 0.815 & 0.786 \\
\hline & $(0.019)$ & $(0.017)$ & $(0.018)$ & $(0.018)$ \\
\hline
\end{tabular}

a Dependent variable: $C A S H$; MODEL A: equation [1] without unemployment rate $\left(\alpha_{2}=0\right)$ and crime indicator $\left(\alpha_{8}=0\right)$; MODEL B: equation [1] without unemployment rate $\left(\alpha_{2}=0\right)$ but including crime indicator; MODEL C: equation [1] without crime indicator $\left(\alpha_{8}=0\right)$ but including unemployment rate; MODEL D: equation [1] including both unemployment rate and crime indicator.

b Standard errors in round brackets; $* *$ statistically significant at $1 \%$; ${ }^{* *}$ statistically significant at $5 \%$;

* statistically significant at $10 \%$. 
Table 2. Average size of underground economy and illegal production as \% of GDP - Random Effects Tobit estimates a

\begin{tabular}{l|rrrr|rrrr}
\hline & \multicolumn{3}{|c|}{ Underground economy } & \multicolumn{3}{c}{ Illegal production } \\
& MODEL A & MODEL B & MODEL C & MODEL D & MODEL A & MODEL B & MODEL C & MODEL D \\
\hline \hline \multirow{2}{*}{ Mean 2005-2008 } & $21.4 \%$ & $16.5 \%$ & $26.1 \%$ & $17.5 \%$ & - & $10.9 \%$ & - & $10.0 \%$ \\
2005 & $17.9 \%$ & $14.5 \%$ & $22.7 \%$ & $14.8 \%$ & - & $10.2 \%$ & - & $9.3 \%$ \\
2006 & $19.2 \%$ & $15.0 \%$ & $23.3 \%$ & $15.9 \%$ & - & $9.6 \%$ & - & $-8.8 \%$ \\
2007 & $23.9 \%$ & $18.0 \%$ & $28.4 \%$ & $19.3 \%$ & - & $11.3 \%$ & $-10.3 \%$ \\
2008 & $24.6 \%$ & $18.5 \%$ & $29.9 \%$ & $19.9 \%$ & - & $12.6 \%$ & - & $11.6 \%$ \\
\hline
\end{tabular}

a Outliers were identified using the Hadi $(1992,1994)$ method: estimates dropped are 28 in MODEL A, 26 in MODEL B, 21 in MODEL C, and 28 in MODEL D.

Table 3. Average size of underground economy and illegal production as \% of GDP - Random Effects GLS estimates a

\begin{tabular}{|c|c|c|c|c|c|c|c|c|}
\hline & \multicolumn{4}{|c|}{ Underground economy } & \multicolumn{4}{|c|}{ Illegal production } \\
\hline & MODEL A & MODEL B & MODEL C & MODEL D & MODEL A & MODEL B & MODEL C & MODEL D \\
\hline Mean 2005-2008 & $25.7 \%$ & $17.9 \%$ & $26.6 \%$ & $18.9 \%$ & - & $10.1 \%$ & - & $9.7 \%$ \\
\hline 2005 & $22.4 \%$ & $15.9 \%$ & $23.1 \%$ & $16.7 \%$ & - & $9.4 \%$ & - & $9.1 \%$ \\
\hline 2006 & $23.0 \%$ & $16.4 \%$ & $23.8 \%$ & $17.3 \%$ & - & $8.9 \%$ & - & $8.6 \%$ \\
\hline 2007 & $28.0 \%$ & $19.4 \%$ & $29.0 \%$ & $20.7 \%$ & - & $10.5 \%$ & - & $10.1 \%$ \\
\hline 2008 & $29.5 \%$ & $19.7 \%$ & $30.5 \%$ & $20.9 \%$ & - & $11.6 \%$ & - & $11.2 \%$ \\
\hline
\end{tabular}

a Outliers were identified using the Hadi $(1992,1994)$ method: estimates dropped are 21 in MODEL A, 27 in MODEL B, 21 in MODEL $\mathrm{C}$, and 27 in MODEL D. 
Table 4. Average size of underground economy and illegal production as \% of GDP - MODEL D with jackknifing (mean 2005-2008) a

\begin{tabular}{l|cc|cc}
\hline & \multicolumn{2}{|c|}{ Underground economy } & \multicolumn{2}{c}{ Illegal production } \\
& Random Effects Tobit & Random Effects GLS & Random Effects Tobit & Random Effects GLS \\
\hline \hline Subset 1 & $17.9 \%$ & $19.0 \%$ & $10.1 \%$ & $9.5 \%$ \\
Subset 2 & $15.7 \%$ & $17.1 \%$ & $11.9 \%$ & $9.9 \%$ \\
Subset 3 & $16.4 \%$ & $17.2 \%$ & $12.0 \%$ & $9.8 \%$ \\
\hline
\end{tabular}

a Observations dropped from the estimation are: the 3 largest towns in the Centre-North (Turin, Milan and Rome) for all years in subset 1, the 3 largest towns in the South (Bari, Naples and Palermo) for all years in subset 2, and the combination of the 6 largest towns in the Centre-North and the South for all years in subset 3.

Before computing average values, outliers were identified using the Hadi (1992, 1994) method.

Table 5. Average size of underground economy and illegal production as \% of GDP - MODEL D with $E V A S 1, E V A S 2$ and $C R I M E$ weighted by an employment concentration index a

\begin{tabular}{|c|c|c|c|c|}
\hline & \multicolumn{2}{|c|}{ Underground economy } & \multicolumn{2}{|c|}{ Illegal production } \\
\hline & Random Effects Tobit & Random Effects GLS & Random Effects Tobit & Random Effects GLS \\
\hline Mean 2005-2008 & $19.7 \%$ & $20.4 \%$ & $11.2 \%$ & $10.7 \%$ \\
\hline 2005 & $16.8 \%$ & $17.8 \%$ & $10.4 \%$ & $9.9 \%$ \\
\hline 2006 & $17.9 \%$ & $18.3 \%$ & $9.9 \%$ & $9.4 \%$ \\
\hline 2007 & $21.6 \%$ & $22.5 \%$ & $11.7 \%$ & $11.2 \%$ \\
\hline 2008 & $22.5 \%$ & $23.0 \%$ & $12.8 \%$ & $12.2 \%$ \\
\hline
\end{tabular}

a Outliers were identified using the Hadi $(1992,1994)$ method: estimates dropped are 25 in the Random Effects Tobit model and 23 in the Random Effects GLS model.

Table 6. Average size of underground economy and illegal production as \% of GDP - MODEL D with drug separated from prostitution (mean 2005-2008) a

\begin{tabular}{cc|cccc}
\hline \multicolumn{2}{c|}{ Underground economy } & \multicolumn{3}{|c}{ Illegal production } \\
RE Tobit & RE GLS & A - DRUG & \multicolumn{3}{c}{ B - PROSTITUTION } \\
\hline \hline $16.9 \%$ & $18.3 \%$ & $8.4 \%$ & RE GLS & RE Tobit & RE GLS \\
\hline
\end{tabular}

a Outliers were identified using the Hadi $(1992,1994)$ method: estimates dropped are 36 in the Random Effects

Tobit model and 37 in the Random Effects GLS model. 
Table 7. Average size of underground economy and illegal production as \% of GDP in Southern and Central-Northern Italian provinces - MODEL D (mean 2005-2008) a

\begin{tabular}{l|cc|cc}
\hline & \multicolumn{2}{|c|}{ Underground economy } & \multicolumn{2}{c}{ Illegal production } \\
& Random Effects Tobit & Random Effects GLS & Random Effects Tobit & Random Effects GLS \\
\hline \hline CENTRE-NORTH & $19.0 \%$ & $21.2 \%$ & $11.5 \%$ & $11.2 \%$ \\
SOUTH & $14.0 \%$ & $13.7 \%$ & $6.7 \%$ & $6.5 \%$ \\
\hline
\end{tabular}

a Outliers were identified using the Hadi (1992, 1994) method: estimates dropped are 28 in the Random Effects

Tobit model and 27 in the Random Effects GLS model.

Table 8. Average size of underground economy and illegal production as \% of GDP in Southern and Central-Northern Italian provinces - MODEL D with jackknifing (mean 2005-2008) a

\begin{tabular}{|c|c|c|c|c|}
\hline & \multicolumn{2}{|c|}{ Underground economy } & \multicolumn{2}{|c|}{ Illegal production } \\
\hline & Random Effects Tobit & Random Effects GLS & Random Effects Tobit & Random Effects GLS \\
\hline \multicolumn{5}{|l|}{ Subset 1} \\
\hline CENTRE-NORTH & $19.5 \%$ & $21.3 \%$ & $11.7 \%$ & $11.0 \%$ \\
\hline SOUTH & $14.3 \%$ & $13.8 \%$ & $6.7 \%$ & $6.4 \%$ \\
\hline \multicolumn{5}{|l|}{ Subset 2} \\
\hline CENTRE-NORTH & $17.4 \%$ & $19.1 \%$ & $13.3 \%$ & $11.1 \%$ \\
\hline SOUTH & $11.5 \%$ & $12.1 \%$ & $8.3 \%$ & $6.9 \%$ \\
\hline \multicolumn{5}{|l|}{ Subset 3} \\
\hline CENTRE-NORTH & $18.1 \%$ & $19.2 \%$ & $13.4 \%$ & $10.9 \%$ \\
\hline SOUTH & $12.1 \%$ & $12.2 \%$ & $8.4 \%$ & $6.9 \%$ \\
\hline
\end{tabular}

a Observations dropped from the estimation are: the 3 largest towns in the Centre-North (Turin, Milan and Rome) for all years in subset 1, the 3 largest towns in the South (Bari, Naples and Palermo) for all years in subset 2, and the combination of the 6 largest towns in the Centre-North and the South for all years in subset 3.

Before computing average values, outliers were identified using the Hadi $(1992,1994)$ method.

Table 9. Average size of underground economy and illegal production as \% of GDP in Southern and Central-Northern Italian provinces - MODEL D with drug separated from prostitution (mean 2005-2008) ${ }^{a}$

\begin{tabular}{l|cc|cccc}
\hline & \multicolumn{2}{|c|}{ Underground economy } & \multicolumn{4}{c}{ Illegal production } \\
& RE Tobit & RE GLS & RE Tobit & RE GLS & RE Tobit & RE GLS \\
& $18.5 \%$ & $20.5 \%$ & $9.6 \%$ & $9.8 \%$ & $2.0 \%$ & $1.9 \%$ \\
CENTRE-NORTH & $13.5 \%$ & $13.5 \%$ & $5.9 \%$ & $6.0 \%$ & $0.9 \%$ & $0.9 \%$ \\
\hline \hline
\end{tabular}

a Outliers were identified using the Hadi $(1992,1994)$ method: estimates dropped are 36 in the Random Effects

Tobit model and 37 in the Random Effects GLS model. 
Figure 1. Geographical distribution of underground economy and illegal production as a \% of GDP by province (Random Effects Tobit estimates on 91 Italian provinces, mean 2005-2008 - MODEL D)

\section{Underground economy}

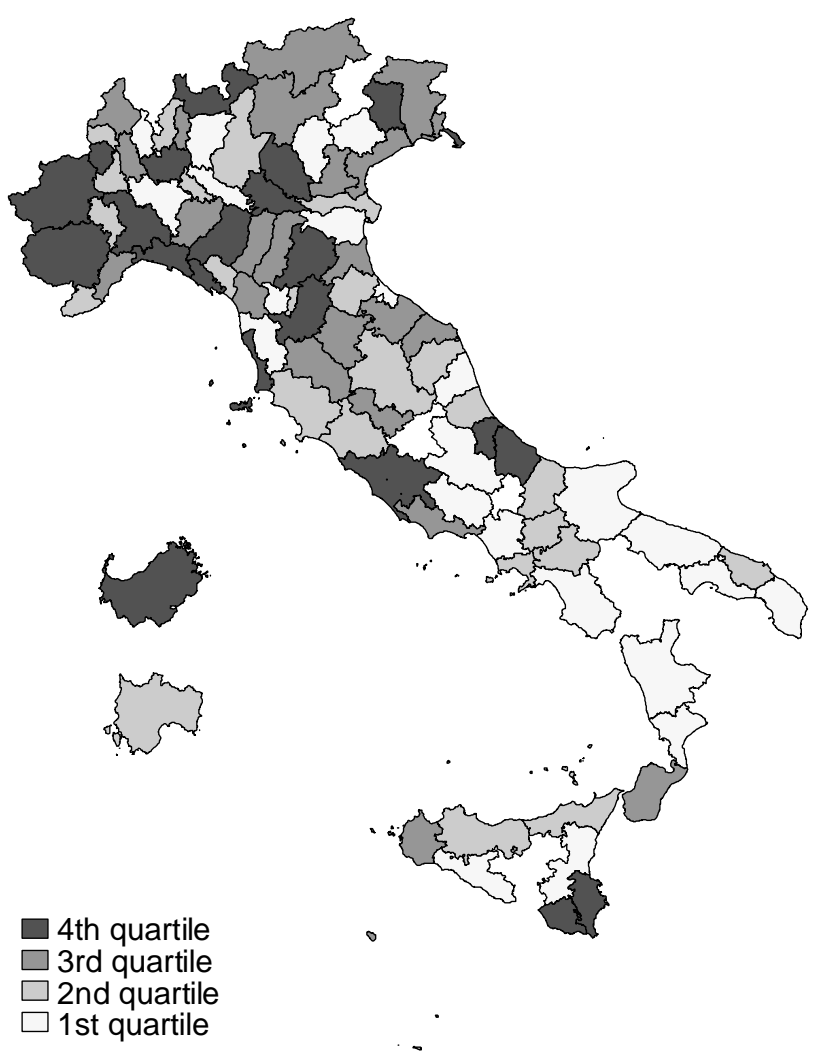

Illegal production

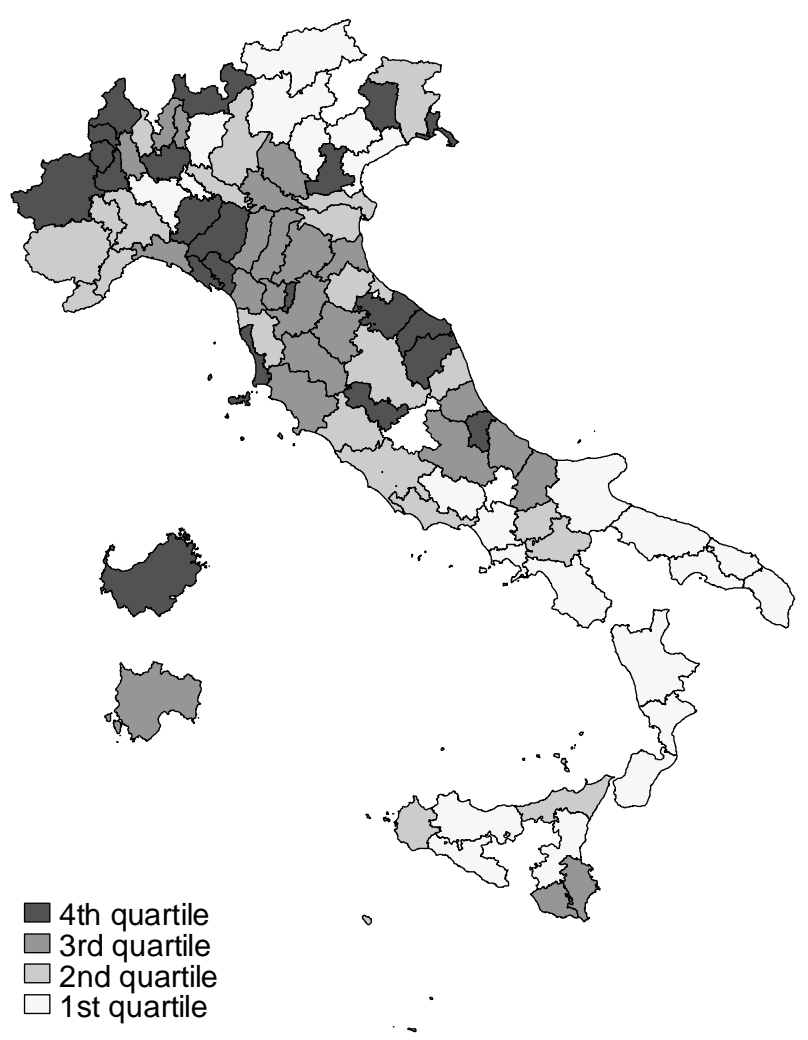




\section{Appendix 1. Flows vs. stocks in the demand equation of cash payments}

The ratio of the value of cash withdrawn from bank accounts to the value of total payments settled by instruments other than cash $(C A S H)$ is the dependent variable in our estimated equation of the demand for cash payments. This represents a measure of the demand for untraced payments per euro of traceable ones (i.e., payments settled by bank transfers, cheques, credit cards).

The transactions theory of money demand relies on liquid assets as such (e.g., M1) rather than on the concept of payment, the latter necessarily implying a cash flow and precise technical and organizational procedures by which these flows circulate in the economy. However, even in the presence of reliable statistics, stock indicators can be highly inaccurate for three reasons: a) quantifying the level of national currency used outside national borders is problematic, and this is particularly true in the euro area after the euro entered circulation in 2002 ; b) a certain amount of money can be held for purposes other than transactions: traditional theories of money demand discuss, for instance, the 'speculative motive' for holding money reserves; c) the velocity of money is assumed to be constant with respect to several GDP components, including the informal sector, without taking into account, inter alia, trade in intermediate goods and services. Hence, there may be compensatory phenomena within the same stock of banknotes in circulation, both between different purposes for holding money reserves, and between the use of cash in the formal and the informal sector. This is confirmed by the recent trend of the currency-to-GDP ratio in the countries belonging to the G10 and to the Eurosystem: the ratio has remained stable or even increased since 2004 in those countries that should have been more affected by the replacement of banknotes with digital money. Similar considerations hold for other stock-based indicators of currency demand, such as the stocks of M1 (currency and deposits repayable on demand). Notice that - although being a signal of a higher preference for liquidity - an increase in a stock-based monetary aggregate is not informative about the underlying reasons, including for instance the rebalancing of portfolio assets, the adjustment in liquidity buffers, the need to hide transactions (whether for evading taxes or because they are illegal). The European Central Bank has noted that, on the occasion of the so-called cash changeover, the stock of euro banknotes in circulation has increased (even compared to M1 or M2) more than the previous circulation of national currencies would have suggested (ECB, 2008). According to he ECB, «this is reasonable, in particular, in an environment of low interest rates and low inflation expectations», not to mention that an estimate up to $20 \%$ percent of 
banknotes in circulation is held outside of the Euro area. It then becomes difficult - if not impossible - to estimate the component of cash held to settle payments within the underground economy using stock infomation. This is the reason why scholars interested in estimating the size of shadow sector using a cash demand approach should select monetary indicators more directly related to the transaction motive.

In order to better clarify this issue, Figure Al shows the recent trends of the currency-to-GDP and the currency-to-M1 ratios as compared to their respective flows in Italy. Two diverging trends can be observed: the stocks show a rising trend, while the flows are declining. An explanation of the increasing trend of stocks is given by the above mentioned explanation provided by the ECB. The decreasing trend of flows is instead consistent with the diffusion of electronic payment instruments in commercial transactions, which allows some substitution between alternative instruments, at least in the formal economy. Furthermore, the common trend of the two flow-based indicators confirms the higher coherence of these indicators with the transaction motive of the demand for cash. The combined evidence of such a "substitution effect' of cash flows and the growing trend of the stock of banknotes suggests a slowing down of the overall velocity of circulation of legal money in order to meet liquidity needs other than purely transactional ones. All these considerations seem to support the criticisms raised to the traditional CDA based on the quantity theory of money.

Figure A1. Monetary aggregates in Italy: stocks vs. flows (index numbers, first semester $2002=1$ )

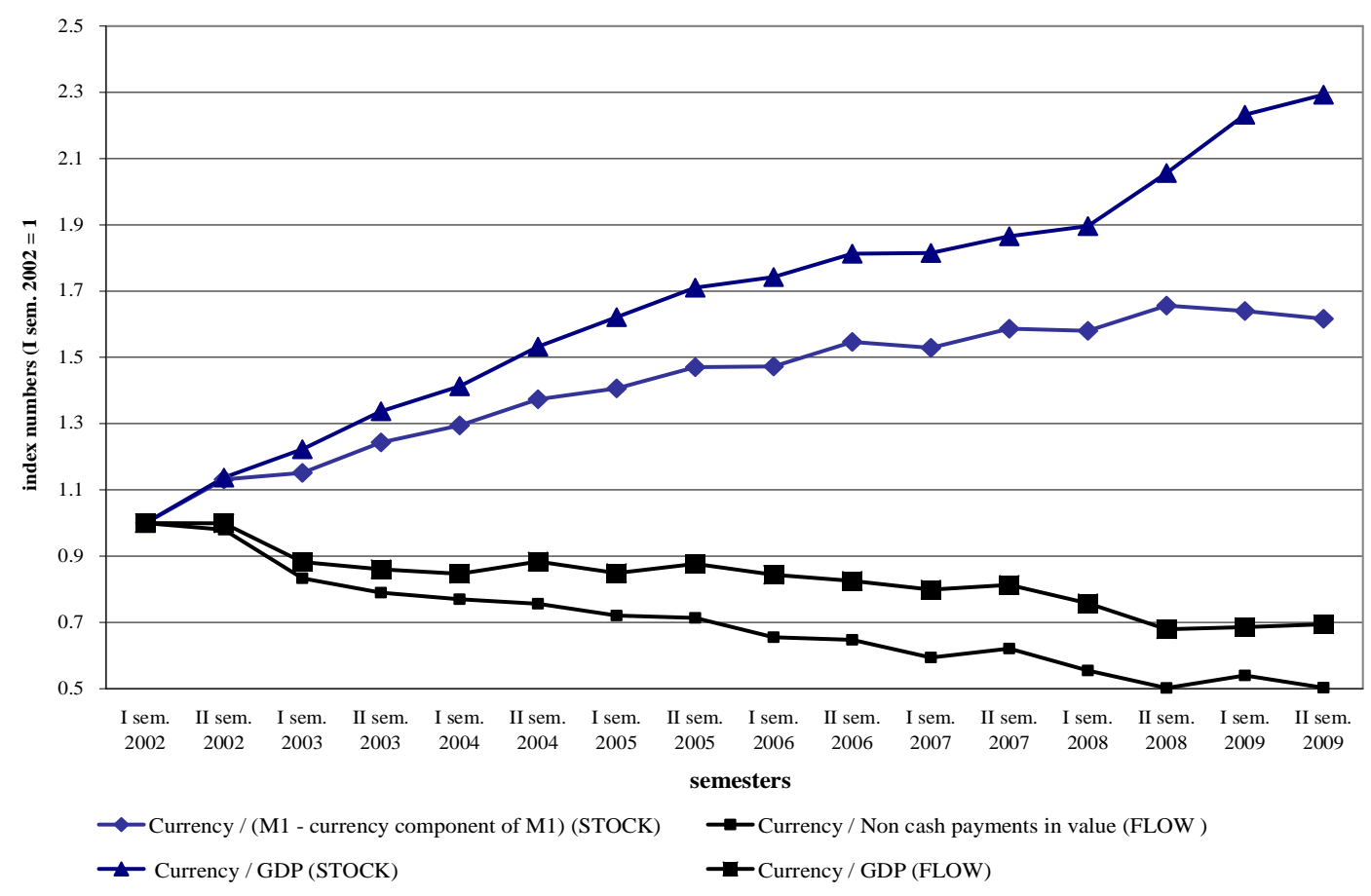

Source: own elaboration on Bank of Italy and ISTAT data. 
Table A1. Pearson, Spearman and Kendall tau-b correlation coefficients on different cash usage indicators ${ }^{\text {a }}$

\begin{tabular}{|c|c|c|c|}
\hline Cash usage indicator & $\begin{array}{l}\text { Total cash withdrawals value flows } \\
\text { on total non cash payments }\end{array}$ & $\begin{array}{l}\text { ATM cash withdrawals } \\
\text { on POS card transactions }\end{array}$ & $\begin{array}{l}\text { Cash expenditure share by } \\
\text { Italian households } \mathrm{d}\end{array}$ \\
\hline & \multicolumn{3}{|c|}{ Pearson correlation } \\
\hline $\begin{array}{l}\text { Total cash withdrawals value } \\
\text { flows on total non cash payments }\end{array}$ & 1 & & \\
\hline $\begin{array}{l}\text { ATM cash withdrawals on POS } \\
\text { card transactions }\end{array}$ & 0.663 & 1 & \\
\hline \multirow[t]{2}{*}{$\begin{array}{l}\text { Cash expenditure share by Italian } \\
\text { households }\end{array}$} & 0.717 & 0.848 & 1 \\
\hline & \multicolumn{3}{|c|}{ Spearman correlation } \\
\hline $\begin{array}{l}\text { Total cash withdrawals value } \\
\text { flows on total non cash payments }\end{array}$ & 1 & & \\
\hline $\begin{array}{l}\text { ATM cash withdrawals on POS } \\
\text { card transactions }\end{array}$ & 0.695 & 1 & \\
\hline \multirow[t]{2}{*}{$\begin{array}{l}\text { Cash expenditure share by Italian } \\
\text { households }\end{array}$} & 0.690 & 0.793 & 1 \\
\hline & \multicolumn{3}{|c|}{ Kendall tau-b correlation } \\
\hline $\begin{array}{l}\text { Total cash withdrawals value } \\
\text { flows on total non cash payments }\end{array}$ & 1 & & \\
\hline $\begin{array}{l}\text { ATM cash withdrawals on POS } \\
\text { card transactions }\end{array}$ & 0.490 & 1 & \\
\hline $\begin{array}{l}\text { Cash expenditure share by Italian } \\
\text { households }\end{array}$ & 0.490 & 0.590 & 1 \\
\hline
\end{tabular}

The direct link between flow-based indicators of currency demand and the transaction motive of the demand for cash can also be highlighted by looking at micro-data on cash purchases collected by the Bank of Italy through the Survey on Household Income and Wealth. Table A1 illustrates the correlation matrix of two different (macro) currency ratios (based on bank cash withdrawals flows divided by other payments transactions) and the percentage of cash purchases on total expenditures declared by the Italian households sample in the period 20062008 (nearly the period considered in this study). The correlation coefficients are positive and significant in all cases. As one would expect, the "ATM cash withdrawals on POS card transactions' ratio shows a higher correlation with the 'Cash expenditure share by Italian households' than the 'Total cash withdrawals value flows to total non cash payments' ratio. In other words, the closer is the monetary indicator to the 'point of sales', the higher is the 
correlation with the household cash expenditures. ${ }^{23}$ Nevertheless, the wider indicator of cash usage 'Total cash withdrawals value flows to total non cash payments' better accounts for the behaviour of all the economic agents - including also private firms and the public sector, besides the household sector - which makes it more appropriate for the purposes of the analysis carried out in this paper.

${ }^{23}$ Exhaustive data on ATM cash withdrawals and POS transactions at regional level are fully available from 2009. Nevertheless, the stability of payment behaviours over time makes the correlation analysis consistent even in the presence of a different period covered by data on cash expenditures. 


\section{Appendix 2. Data and robustness check estimates}

This study uses an original dataset on a balanced panel of 91 Italian provinces observed over the period 2005-2008. This dataset merges information of four different sources: Bank of Italy (BdI), Guardia di Finanza (GdF, the Italian Tax Police), Istat (the Italian National Statistical Office), and Eurostat (the Statistical Office of the European Union). All monetary variables are provided by BdI. Data on provincial GDP are provided by Eurostat. The proxies for tax evasion are computed using data on GdF fiscal inspections for the period 2005-2008. The crime index uses information on criminal offences downloaded from Istat website http://giustiziaincifre.istat.it.

Table A2. Data description (definition of variables and data sources)

\begin{tabular}{lll}
\hline Variable & Definition & Source \\
\hline \hline CASH & $\begin{array}{l}\text { Ratio of the value of cash withdrawn from bank accounts to the } \\
\text { value of total payments settled by instruments other than cash }\end{array}$ & BdI \\
\hline
\end{tabular}

Structural factors

YPC Provincial GDP per capita

URATE Provincial unemployment rate

$B A N K \quad$ Per capita number of banking accounts

ELECTRO Ratio of the value of transactions settled by electronic payments to GDP
Rate of interest on bank deposits
Eurostat

Istat

BdI

BdI and Eurostat BdI

Tax evasion

EVAS1 Number of specific tax audits in a province divided by its sample GdF and Eurostat mean value (weighted by a GDP concentration index)

EVAS2 Ratio of the number of positive audits on cash registers and tax GdF and Eurostat receipts to the number of existing POS in the province (weighted by a GDP concentration index)

Criminal economy

CRIME Share of crimes violating laws on drugs and prostitution over the total number of reported crimes (weighted by a GDP Istat and Eurostat concentration index)

$D R U G$ Share of crimes violating laws on drugs over the total number of Istat and Eurostat reported crimes (weighted by a GDP concentration index)

PROST Share of crimes violating laws on prostitution over the total number

Istat and Eurostat of reported crimes (weighted by a GDP concentration index) 
Table A3. Descriptive statistics

\begin{tabular}{|c|c|c|c|c|c|c|}
\hline \multicolumn{7}{|c|}{ Standard Deviation } \\
\hline Variable & Mean & Total & Between & Within & Min & Max \\
\hline \multicolumn{7}{|c|}{$I T A L Y$ a } \\
\hline CASH & 0.108 & 0.048 & 0.046 & 0.013 & 0.010 & 0.236 \\
\hline$Y P C\left(\times 10^{4} €\right)$ & 2.491 & 0.596 & 0.590 & 0.099 & 1.235 & 3.908 \\
\hline$U R A T E$ & 0.066 & 0.030 & 0.038 & 0.010 & 0.019 & 0.192 \\
\hline$B A N K$ & 0.584 & 0.193 & 0.189 & 0.042 & 0.236 & 1.177 \\
\hline ELECTRO & 2.100 & 1.728 & 1.598 & 0.672 & 0.538 & 16.638 \\
\hline$I N T$ & 1.247 & 0.488 & 0.265 & 0.410 & 0.472 & 2.909 \\
\hline$E V A S 1$ & 1.151 & 0.594 & 0.575 & 0.159 & 0.222 & 3.839 \\
\hline$E V A S 2$ & 0.204 & 0.215 & 0.207 & 0.063 & 0.001 & 1.233 \\
\hline CRIME & 0.023 & 0.020 & 0.019 & 0.004 & 0.001 & 0.116 \\
\hline$D R U G$ & 0.022 & 0.019 & 0.019 & 0.004 & 0.001 & 0.112 \\
\hline PROST & 0.001 & 0.001 & 0.001 & 0.001 & 0.000 & 0.008 \\
\hline \multicolumn{7}{|c|}{ CENTRE-NORTH b } \\
\hline$C A S H$ & 0.090 & 0.041 & 0.039 & 0.012 & 0.010 & 0.204 \\
\hline$Y P C\left(\times 10^{4} €\right)$ & 2.823 & 0.335 & 0.318 & 0.110 & 2.061 & 3.908 \\
\hline URATE & 0.045 & 0.016 & 0.015 & 0.006 & 0.019 & 0.102 \\
\hline$B A N K$ & 0.684 & 0.129 & 0.125 & 0.036 & 0.304 & 1.177 \\
\hline ELECTRO & 2.399 & 1.962 & 1.802 & 0.800 & 0.538 & 16.638 \\
\hline$I N T$ & 1.299 & 0.504 & 0.261 & 0.432 & 0.472 & 2.909 \\
\hline$E V A S I$ & 1.067 & 0.522 & 0.507 & 0.136 & 0.221 & 2.746 \\
\hline$E V A S 2$ & 0.149 & 0.186 & 0.178 & 0.059 & 0.001 & 1.233 \\
\hline CRIME & 0.022 & 0.021 & 0.021 & 0.003 & 0.001 & 0.115 \\
\hline$D R U G$ & 0.021 & 0.020 & 0.020 & 0.003 & 0.001 & 0.112 \\
\hline PROST & 0.001 & 0.001 & 0.001 & 0.001 & 0.000 & 0.008 \\
\hline \multicolumn{7}{|c|}{$\operatorname{SOUTH}^{\mathrm{c}}$} \\
\hline CASH & 0.148 & 0.038 & 0.036 & 0.016 & 0.063 & 0.236 \\
\hline$Y P C\left(\times 10^{4} €\right)$ & 1.703 & 0.216 & 0.210 & 0.062 & 1.234 & 2.218 \\
\hline URATE & 0.116 & 0.032 & 0.028 & 0.016 & 0.053 & 0.192 \\
\hline$B A N K$ & 0.347 & 0.077 & 0.057 & 0.053 & 0.236 & 0.581 \\
\hline ELECTRO & 1.390 & 0.478 & 0.479 & 0.077 & 0.806 & 2.723 \\
\hline$I N T$ & 1.122 & 0.423 & 0.235 & 0.355 & 0.474 & 2.480 \\
\hline EVASI & 1.350 & 0.699 & 0.678 & 0.205 & 0.387 & 3.839 \\
\hline EVAS2 & 0.335 & 0.224 & 0.215 & 0.0718 & 0.037 & 0.983 \\
\hline CRIME & 0.025 & 0.016 & 0.015 & 0.006 & 0.003 & 0.095 \\
\hline$D R U G$ & 0.025 & 0.016 & 0.015 & 0.006 & 0.004 & 0.094 \\
\hline PROST & 0.001 & 0.001 & 0.001 & 0.000 & 0.000 & 0.004 \\
\hline
\end{tabular}

a Figures based on a balanced panel of 91 provinces observed in 2005-2008 (364 total observations).

b Figures based on a balanced panel of 64 provinces observed in 2005-2008 (256 total observations).

c Figures based on a balanced panel of 27 provinces observed in 2005-2008 (108 total observations). 
Table A4. Estimated demand for cash payments (Random Effects GLS model - 91 Italian provinces, 2005-2008) ${ }^{\text {a }}$

\begin{tabular}{|c|c|c|c|c|}
\hline Regressors $^{\text {b }}$ & MODEL A & MODEL B & MODEL C & MODEL D \\
\hline \multirow[t]{2}{*}{$Y P C$} & $-0.027 * * *$ & $-0.024 * * *$ & $-0.021 * * *$ & $-0.018 * *$ \\
\hline & $(0.006)$ & $(0.006)$ & $(0.008)$ & $(0.008)$ \\
\hline \multirow[t]{2}{*}{$U R A T E$} & - & - & $0.114^{*}$ & $0.110^{*}$ \\
\hline & & & $(0.065)$ & $(0.064)$ \\
\hline \multirow[t]{2}{*}{$B A N K$} & $-0.046^{* * *}$ & $-0.054^{* * *}$ & $-0.044 * * *$ & $-0.053 * * *$ \\
\hline & $(0.015)$ & $(0.015)$ & $(0.015)$ & $(0.015)$ \\
\hline \multirow[t]{2}{*}{ ELECTRO } & $-0.006^{* * *}$ & $-0.005^{* * *}$ & $-0.006^{* * *}$ & $-0.006^{* * *}$ \\
\hline & $(0.001)$ & $(0.001)$ & $(0.001)$ & $(0.001)$ \\
\hline \multirow[t]{2}{*}{$I N T$} & $-0.011 * * *$ & $-0.010 * * *$ & $-0.011 * * *$ & $-0.011 * * *$ \\
\hline & $(0.002)$ & $(0.002)$ & $(0.002)$ & $(0.002)$ \\
\hline \multirow[t]{2}{*}{$E V A S 1$} & $0.009 * *$ & $0.007^{*}$ & $0.009 * *$ & $0.007 * *$ \\
\hline & $(0.004)$ & $(0.004)$ & $(0.004)$ & $(0.004)$ \\
\hline \multirow[t]{2}{*}{$E V A S 2$} & $0.018^{*}$ & $0.008 *$ & $0.020^{*}$ & $0.010^{*}$ \\
\hline & $(0.011)$ & $(0.005)$ & $(0.011)$ & $(0.010)$ \\
\hline \multirow[t]{2}{*}{ CRIME } & - & $0.265^{* * *}$ & - & $0.255^{* * *}$ \\
\hline & & $(0.073)$ & & $(0.069)$ \\
\hline \multirow[t]{2}{*}{ Constant } & $0.212^{* * *}$ & $0.206^{* * *}$ & $0.189 * * *$ & $0.183^{* * *}$ \\
\hline & $(0.015)$ & $(0.016)$ & $(0.026)$ & $(0.026)$ \\
\hline Observations & 364 & 364 & 364 & 364 \\
\hline Overall $\mathrm{R}^{2}$ & 0.67 & 0.67 & 0.68 & 0.68 \\
\hline Wald statistic $\left(\chi^{2}\right)$ & $299.84^{* * *}$ & $272.18^{* * *}$ & $323.00^{* * *}$ & $294.56^{* * *}$ \\
\hline$\sigma_{u}$ & 0.023 & 0.023 & 0.022 & 0.022 \\
\hline$\sigma_{e}$ & 0.012 & 0.012 & 0.012 & 0.012 \\
\hline$\rho$ & 0.789 & 0.789 & 0.773 & 0.776 \\
\hline
\end{tabular}

a Dependent variable: $C A S H$; MODEL A: equation [1] without unemployment rate $\left(\alpha_{2}=0\right)$ and crime indicator $\left(\alpha_{8}=0\right)$; MODEL B: equation [1] without unemployment rate $\left(\alpha_{2}=0\right)$ but including crime indicator; MODEL C: equation [1] without crime indicator $\left(\alpha_{8}=0\right)$ but including unemployment rate; MODEL D: equation [1] including both unemployment rate and crime indicator.

b Robust (clustered) standard errors in round brackets; *** statistically significant at $1 \%$; ** statistically significant at $5 \% ;{ }^{*}$ statistically significant at $10 \%$. 
Table A5. Estimated demand for cash payments - MODEL D with controls for time period effects a

\begin{tabular}{|c|c|c|}
\hline Regressors ${ }^{b}$ & Random Effects Tobit & Random Effects GLS \\
\hline$Y P C$ & $-0.015(0.006)^{* *}$ & $-0.017(0.009)^{*}$ \\
\hline$Y P C \times T 2$ & $-0.001(0.006)$ & $-0.001(0.005)$ \\
\hline$U R A T E$ & $0.120(0.056)^{* *}$ & $0.150(0.059)^{* *}$ \\
\hline$U R A T E \times T 2$ & $-0.120(0.104)$ & $-0.119(0.092)$ \\
\hline$B A N K$ & $-0.072(0.019)^{* * *}$ & $-0.057(0.019)^{* * *}$ \\
\hline$B A N K \times T 2$ & $-0.010(0.016)$ & $-0.012(0.013)$ \\
\hline ELECTRO & $-0.006(0.001)^{* * *}$ & $-0.006(0.001)^{* * *}$ \\
\hline$E L E C T R O \times T 2$ & $0.001(0.001)$ & $0.001(0.001)$ \\
\hline$I N T$ & $-0.013(0.002)^{* * *}$ & $-0.012(0.003)^{* * *}$ \\
\hline$I N T \times T 2$ & $0.004(0.004)$ & $0.003(0.003)$ \\
\hline$E V A S 1$ & $0.006(0.002)^{* *}$ & $0.007(0.004)^{*}$ \\
\hline$E V A S 1 \times T 2$ & $0.000(0.003)$ & $0.000(0.003)$ \\
\hline$E V A S 2$ & $0.014(0.007)^{* *}$ & $0.010(0.005)^{* *}$ \\
\hline$E V A S 2 \times T 2$ & $0.011(0.008)$ & $0.010(0.010)$ \\
\hline CRIME & $0.250(0.075)^{* * *}$ & $0.250(0.105)^{* *}$ \\
\hline$C R I M E \times T 2$ & $0.025(0.089)$ & $0.039(0.125)$ \\
\hline$T 2$ & $0.009(0.018)$ & $0.012(0.014)$ \\
\hline Constant & $0.195(0.014)^{* * *}$ & $0.180(0.029)^{* * *}$ \\
\hline Observations & 364 & 364 \\
\hline Log-likelihood & 972.15 & - \\
\hline Overall $\mathbf{R}^{2 \text { c }}$ & 0.14 & 0.68 \\
\hline Wald statistic $\left(\chi^{2}\right)$ & $2501.47 * * *$ & $417.81^{* * *}$ \\
\hline$\sigma_{u}$ & 0.023 & 0.021 \\
\hline$\sigma_{e}$ & 0.012 & 0.012 \\
\hline$\rho$ & 0.795 & 0.758 \\
\hline
\end{tabular}

a Dependent variable: CASH. Dummy T2 $=0$ in the years 2005-2006 and $=1$ in the years 2007-2008.

b Standard errors reported in round brackets are robust (clustered) estimates in the Random Effects GLS model; *** statistically significant at $1 \%$; ** statistically significant at $5 \%$; statistically significant at $10 \%$

c The value reported for the Random Effects Tobit model is the McFadden's pseudo- $\mathrm{R}^{2}$. 
Table A6. Estimated demand for cash payments - MODEL D with jackknifing: subset $1^{\text {a }}$

\begin{tabular}{|c|c|c|}
\hline Regressors $^{b}$ & Random Effects Tobit & Random Effects GLS \\
\hline \multirow[t]{2}{*}{$Y P C$} & $-0.014^{* * *}$ & $-0.017 * *$ \\
\hline & $(0.005)$ & $(0.009)$ \\
\hline \multirow[t]{2}{*}{$U R A T E$} & $0.110^{* *}$ & $0.105^{*}$ \\
\hline & $(0.047)$ & $(0.056)$ \\
\hline \multirow[t]{2}{*}{$B A N K$} & $-0.068 * * *$ & $-0.056^{* * *}$ \\
\hline & $(0.012)$ & $(0.015)$ \\
\hline \multirow[t]{2}{*}{ ELECTRO } & $-0.006^{* * *}$ & $-0.006^{* * *}$ \\
\hline & $(0.001)$ & $(0.002)$ \\
\hline \multirow[t]{2}{*}{$I N T$} & $-0.012^{* * *}$ & $-0.012^{* * *}$ \\
\hline & $(0.002)$ & $(0.002)$ \\
\hline \multirow[t]{2}{*}{$E V A S 1$} & $0.006 * * *$ & $0.007 * *$ \\
\hline & $(0.002)$ & $(0.004)$ \\
\hline \multirow[t]{2}{*}{$E V A S 2$} & $0.018 * * *$ & $0.011^{*}$ \\
\hline & $(0.006)$ & $(0.006)$ \\
\hline \multirow[t]{2}{*}{ CRIME } & $0.266^{* * *}$ & $0.251^{* * *}$ \\
\hline & $(0.063)$ & $(0.097)$ \\
\hline \multirow[t]{2}{*}{ Constant } & $0.190 * * *$ & $0.186^{* * *}$ \\
\hline & $(0.013)$ & $(0.027)$ \\
\hline Observations & 352 & 352 \\
\hline Log-likelihood & 934.02 & - \\
\hline Overall $\mathrm{R}^{2 \mathrm{c}}$ & 0.14 & 0.66 \\
\hline Wald statistic $\left(\chi^{2}\right)$ & $1740.47 * * *$ & $317.96^{* * *}$ \\
\hline$\sigma_{u}$ & 0.023 & 0.022 \\
\hline$\sigma_{e}$ & 0.012 & 0.012 \\
\hline$\rho$ & 0.785 & 0.775 \\
\hline
\end{tabular}

a Dependent variable: $C A S H$; the 12 observations dropped from the estimation in subset 1 correspond to the 3 largest towns in the Centre-North for all years (Turin, Milan and Rome).

b Standard errors reported in round brackets are robust (clustered) estimates in the Random Effects GLS model; *** statistically significant at 1\%; ** statistically significant at $5 \% ;{ }^{*}$ statistically significant at $10 \%$.

c The value reported for the Random Effects Tobit model is the McFadden's pseudo- $R^{2}$. 
Table A7. Estimated demand for cash payments - MODEL D with jackknifing: subset 2 a

\begin{tabular}{|c|c|c|}
\hline Regressors $^{b}$ & Random Effects Tobit & Random Effects GLS \\
\hline \multirow[t]{2}{*}{$Y P C$} & $-0.023 * * *$ & $-0.023 * * *$ \\
\hline & $(0.005)$ & $(0.008)$ \\
\hline \multirow[t]{2}{*}{$U R A T E$} & $0.052^{*}$ & $0.073^{*}$ \\
\hline & $(0.028)$ & $(0.044)$ \\
\hline \multirow[t]{2}{*}{$B A N K$} & $-0.062 * * *$ & $-0.052 * * *$ \\
\hline & $(0.011)$ & $(0.015)$ \\
\hline \multirow[t]{2}{*}{ ELECTRO } & $-0.005 * * *$ & $-0.005^{* * *}$ \\
\hline & $(0.001)$ & $(0.001)$ \\
\hline \multirow[t]{2}{*}{$I N T$} & $-0.009 * * *$ & $-0.009 * * *$ \\
\hline & $(0.002)$ & $(0.002)$ \\
\hline \multirow[t]{2}{*}{$E V A S 1$} & $0.006^{* * *}$ & $0.007 *$ \\
\hline & $(0.002)$ & $(0.004)$ \\
\hline \multirow[t]{2}{*}{$E V A S 2$} & $0.010^{*}$ & $0.008 *$ \\
\hline & $(0.005)$ & $(0.005)$ \\
\hline \multirow[t]{2}{*}{ CRIME } & $0.303 * * *$ & $0.253^{* * *}$ \\
\hline & $(0.060)$ & $(0.096)$ \\
\hline \multirow[t]{2}{*}{ Constant } & 0.211 & $0.195 * * *$ \\
\hline & $(0.013)$ & $(0.026)$ \\
\hline Observations & 352 & 352 \\
\hline Log-likelihood & 944.97 & - \\
\hline Overall $\mathbf{R}^{2 \mathrm{c}}$ & 0.14 & 0.68 \\
\hline Wald statistic $\left(\chi^{2}\right)$ & $2870.32^{* * *}$ & $285.28 * * *$ \\
\hline$\sigma_{u}$ & 0.023 & 0.022 \\
\hline$\sigma_{e}$ & 0.011 & 0.011 \\
\hline$\rho$ & 0.799 & 0.794 \\
\hline
\end{tabular}

a Dependent variable: $C A S H$; the 12 observations dropped from the estimation in subset 2 correspond to the 3 largest towns in the South for all years (Bari, Naples and Palermo).

b Standard errors reported in round brackets are robust (clustered) estimates in the Random Effects GLS model; *** statistically significant at 1\%; ** statistically significant at $5 \% ;{ }^{*}$ statistically significant at $10 \%$.

c The value reported for the Random Effects Tobit model is the McFadden's pseudo- ${ }^{2}$. 
Table A8. Estimated demand for cash payments - MODEL D with jackknifing: subset 3 a

\begin{tabular}{|c|c|c|}
\hline Regressors $^{b}$ & Random Effects Tobit & Random Effects GLS \\
\hline \multirow[t]{2}{*}{$Y P C$} & $-0.020 * * *$ & $-0.022 * * *$ \\
\hline & $(0.007)$ & $(0.008)$ \\
\hline \multirow[t]{2}{*}{$U R A T E$} & $0.073^{*}$ & $0.068 *$ \\
\hline & $(0.037)$ & $(0.035)$ \\
\hline \multirow[t]{2}{*}{$B A N K$} & $-0.064 * * *$ & $-0.055 * * *$ \\
\hline & $(0.012)$ & $(0.015)$ \\
\hline \multirow[t]{2}{*}{ ELECTRO } & $-0.006^{* * *}$ & $-0.006^{* * *}$ \\
\hline & $(0.001)$ & $(0.002)$ \\
\hline \multirow[t]{2}{*}{$I N T$} & $-0.010 * * *$ & $-0.010 * * *$ \\
\hline & $(0.002)$ & $(0.002)$ \\
\hline \multirow[t]{2}{*}{$E V A S 1$} & $0.006^{* * *}$ & $0.007 *$ \\
\hline & $(0.002)$ & $(0.004)$ \\
\hline \multirow[t]{2}{*}{$E V A S 2$} & $0.011^{*}$ & $0.009 *$ \\
\hline & $(0.007)$ & $(0.005)$ \\
\hline \multirow[t]{2}{*}{ CRIME } & $0.305^{* * *}$ & $0.250 * * *$ \\
\hline & $(0.062)$ & $(0.097)$ \\
\hline \multirow[t]{2}{*}{ Constant } & $0.205 * * *$ & $0.197 * * *$ \\
\hline & $(0.018)$ & $(0.026)$ \\
\hline Observations & 340 & 340 \\
\hline Log-likelihood & 912.20 & - \\
\hline Overall $\mathbf{R}^{2 \mathrm{c}}$ & 0.14 & 0.66 \\
\hline Wald statistic $\left(\chi^{2}\right)$ & $1956.23^{* * *}$ & $322.16^{* * *}$ \\
\hline$\sigma_{u}$ & 0.023 & 0.022 \\
\hline$\sigma_{e}$ & 0.011 & 0.011 \\
\hline$\rho$ & 0.796 & 0.793 \\
\hline
\end{tabular}

a Dependent variable: $C A S H$; the 24 observations dropped from the estimation in subset 3 correspond to the combination of the 6 largest towns in the Centre-North and the South for all years.

b Standard errors reported in round brackets are robust (clustered) estimates in the Random Effects GLS model; *** statistically significant at 1\%; ** statistically significant at $5 \% ;{ }^{*}$ statistically significant at $10 \%$.

c The value reported for the Random Effects Tobit model is the McFadden's pseudo- ${ }^{2}$. 
Table A9. Estimated demand for cash payments a - MODEL D with EVAS1, $E V A S 2$ and $C R I M E$ weighted by an employment concentration index

\begin{tabular}{|c|c|c|}
\hline Regressors $^{b}$ & Random Effects Tobit & Random Effects GLS \\
\hline \multirow[t]{2}{*}{$Y P C$} & $-0.019 * * *$ & $-0.022 * * *$ \\
\hline & $(0.004)$ & $(0.008)$ \\
\hline \multirow[t]{2}{*}{$U R A T E$} & $0.077^{*}$ & $0.088^{*}$ \\
\hline & $(0.044)$ & $(0.045)$ \\
\hline \multirow[t]{2}{*}{$B A N K$} & $-0.071 * * *$ & $-0.055 * * *$ \\
\hline & $(0.011)$ & $(0.015)$ \\
\hline \multirow[t]{2}{*}{ ELECTRO } & $-0.005^{* * *}$ & $-0.005^{* * *}$ \\
\hline & $(0.001)$ & $(0.001)$ \\
\hline \multirow[t]{2}{*}{$I N T$} & $-0.011 * * *$ & $-0.010^{* * *}$ \\
\hline & $(0.002)$ & $(0.002)$ \\
\hline \multirow[t]{2}{*}{$E V A S 1$} & $0.006^{* * *}$ & $0.007 *$ \\
\hline & $(0.002)$ & $(0.004)$ \\
\hline \multirow[t]{2}{*}{$E V A S 2$} & $0.017 * * *$ & $0.015^{* *}$ \\
\hline & $(0.005)$ & $(0.013)$ \\
\hline \multirow[t]{2}{*}{ CRIME } & $0.277 * * *$ & $0.263^{* * *}$ \\
\hline & $(0.067)$ & $(0.095)$ \\
\hline \multirow[t]{2}{*}{ Constant } & $0.204^{* * *}$ & $0.196^{* * *}$ \\
\hline & $(0.011)$ & $(0.025)$ \\
\hline Observations & 364 & 364 \\
\hline Log-likelihood & 967.45 & - \\
\hline Overall $\mathbf{R}^{2 \mathrm{c}}$ & 0.14 & 0.68 \\
\hline Wald statistic $\left(\chi^{2}\right)$ & $2680.17^{* * *}$ & $277.85 * * *$ \\
\hline$\sigma_{u}$ & 0.023 & 0.022 \\
\hline$\sigma_{e}$ & 0.012 & 0.012 \\
\hline$\rho$ & 0.778 & 0.773 \\
\hline
\end{tabular}

a Dependent variable: $C A S H$.

b Standard errors reported in round brackets are robust (clustered) estimates in the Random Effects GLS model; $* * *$ statistically significant at $1 \%$; ** statistically significant at $5 \%$; ${ }^{*}$ statistically significant at $10 \%$.

c The value reported for the Random Effects Tobit model is the McFadden's pseudo- $\mathrm{R}^{2}$. 
Table A10. Estimated demand for cash payments a - MODEL D with drug separated from prostitution

\begin{tabular}{|c|c|c|}
\hline Regressors ${ }^{b}$ & Random Effects Tobit & Random Effects GLS \\
\hline \multirow[t]{2}{*}{$Y P C$} & $-0.023 * * *$ & $-0.019 * *$ \\
\hline & $(0.005)$ & $(0.008)$ \\
\hline \multirow[t]{2}{*}{$U R A T E$} & $0.062 *$ & $0.108 * *$ \\
\hline & $(0.036)$ & $(0.054)$ \\
\hline \multirow[t]{2}{*}{$B A N K$} & $-0.057 * * *$ & $-0.052 * * *$ \\
\hline & $(0.012)$ & $(0.015)$ \\
\hline \multirow[t]{2}{*}{ ELECTRO } & $-0.005 * * *$ & $-0.006^{* * *}$ \\
\hline & $(0.001)$ & $(0.001)$ \\
\hline \multirow[t]{2}{*}{$I N T$} & $-0.010 * * *$ & $-0.011 * * *$ \\
\hline & $(0.002)$ & $(0.002)$ \\
\hline \multirow[t]{2}{*}{$E V A S 1$} & $0.006^{* * *}$ & $0.007 * *$ \\
\hline & $(0.002)$ & $(0.004)$ \\
\hline \multirow[t]{2}{*}{$E V A S 2$} & $0.016^{* *}$ & $0.011^{*}$ \\
\hline & $(0.005)$ & $(0.006)$ \\
\hline \multirow[t]{2}{*}{$D R U G$} & $0.239^{* * *}$ & $0.235^{* * *}$ \\
\hline & $(0.066)$ & $(0.102)$ \\
\hline \multirow[t]{2}{*}{ PROST } & 0.941 & 0.925 \\
\hline & $(0.775)$ & $(1.044)$ \\
\hline \multirow[t]{2}{*}{ Constant } & $0.208 * * *$ & $0.184^{* * *}$ \\
\hline & $(0.012)$ & $(0.026)$ \\
\hline Observations & 364 & 364 \\
\hline Log-likelihood & 966.57 & - \\
\hline Overall $\mathrm{R}^{2 \mathrm{c}}$ & 0.14 & 0.68 \\
\hline Wald statistic $\left(\chi^{2}\right)$ & $2712.14^{* * *}$ & $305.93^{* * *}$ \\
\hline$\sigma_{u}$ & 0.022 & 0.022 \\
\hline$\sigma_{e}$ & 0.012 & 0.012 \\
\hline$\rho$ & 0.785 & 0.778 \\
\hline
\end{tabular}

a Dependent variable: $C A S H$.

b Standard errors reported in round brackets are robust (clustered) estimates in the Random Effects GLS model; *** statistically significant at 1\%; ** statistically significant at $5 \%$; ${ }^{*}$ statistically significant at $10 \%$.

c The value reported for the Random Effects Tobit model is the McFadden's pseudo- $\mathrm{R}^{2}$. 